\title{
ENERGY HARVESTING FROM EXERCISE MACHINES: BUCK-BOOST CONVERTER DESIGN
}

\author{
A Thesis \\ presented to \\ the Faculty of California Polytechnic State University, \\ San Luis Obispo
}

\author{
In Partial Fulfillment \\ of the Requirements for the Degree \\ Master of Science in Electrical Engineering
}

by

Andrew Forster

March 2017 
(C) 2017

Andrew Forster

ALL RIGHTS RESERVED 


\section{COMMITTEE MEMBERSHIP}

TITLE: Energy Harvesting From Exercise Machines:

Buck-Boost Converter Design

AUTHOR: Andrew Forster

DATE SUBMITTED: March 2017

COMMITTEE CHAIR: David Braun, Ph.D.

Professor of Electrical Engineering

COMMITTEE MEMBER: Taufik, Ph.D.

Professor of Electrical Engineering

COMMITTEE MEMBER: Tina Smilkstein, Ph.D.

Professor of Electrical Engineering 


\author{
ABSTRACT \\ Energy Harvesting from Exercise Machines: Buck-Boost Converter Design \\ Andrew Forster
}

This report details the design and implementation of a switching DC-DC converter for use in the Energy Harvesting From Exercise Machines (EHFEM) project. It uses a fourswitch, buck-boost topology to regulate the wide, 5-60 V output of an elliptical machine to $36 \mathrm{~V}$, suitable as input for a microinverter to reclaim the energy for the electrical grid. Successful implementation reduces heat emissions from electrical energy originally wasted as heat, and facilitates a financial and environmental benefit from reduced net energy consumption.

Keywords: DC-DC converter, switching converter, four switch buck boost, nonisolated, EHFEM 


\section{TABLE OF CONTENTS}

Page

LIST OF TABLES $\ldots \ldots \ldots \ldots \ldots \ldots \ldots \ldots$ viii

LIST OF FIGURES $\ldots \ldots \ldots \ldots \ldots \ldots \ldots \ldots \ldots$ ix

\section{CHAPTER}

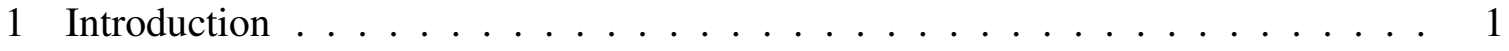

2 Project Planning . . . . . . . . . . . . . . . . . . 3

2.1 Customer Needs Assessment $\ldots \ldots \ldots \ldots$

2.2 Requirements and Specifications $\ldots \ldots \ldots \ldots \ldots$

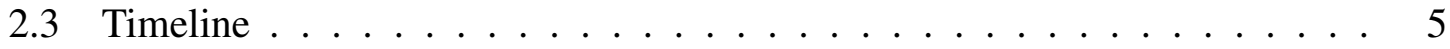

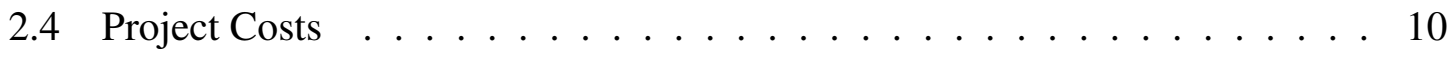

3 Functional Decomposition $\ldots \ldots \ldots \ldots \ldots$

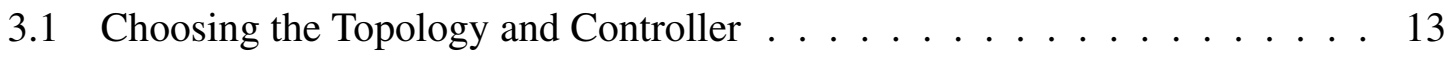

3.2 Feedback Calculations . . . . . . . . . . . . . . . . . . . 14

3.3 Switching vs. Conduction Losses . . . . . . . . . . . . . . . 16

4 Circuit Design and Simulation $\ldots \ldots \ldots \ldots$

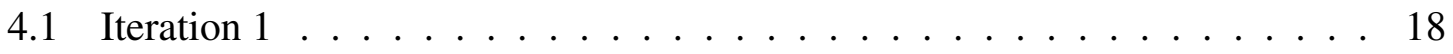

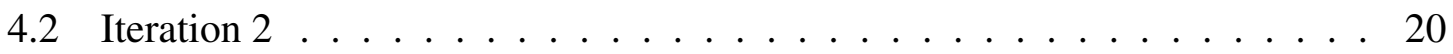

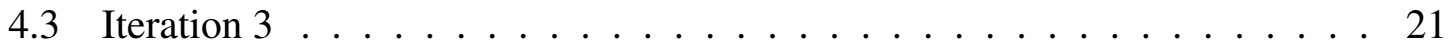

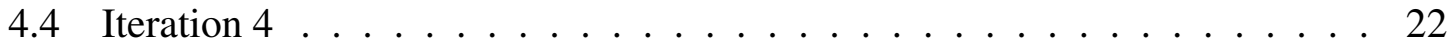

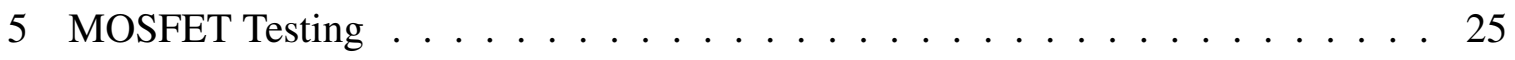

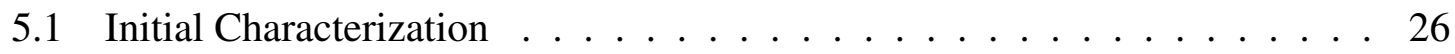




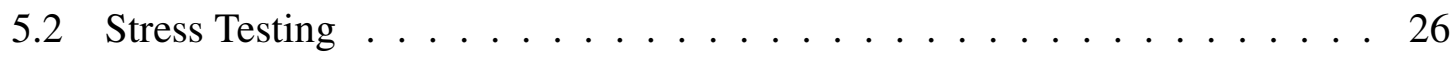

5.3 Results . . . . . . . . . . . . . . . . . . . . . . . . . . . . . 29

5.4 Conclusion . . . . . . . . . . . . . . . . . . 31

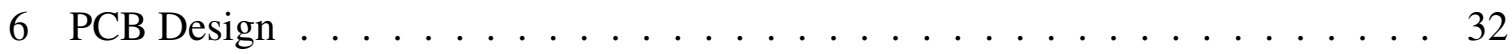

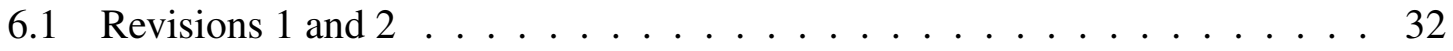

6.1 .1 Switching Software . . . . . . . . . . . . . 34

6.2 Revision $3 \ldots \ldots \ldots \ldots \ldots \ldots \ldots$. . . . . . . . . . . . . . . . . . . .

7 Converter Testing . . . . . . . . . . . . . . . . . . . . 37

7.1 Converter Functional Tests _ . . . . . . . . . . . . . . . . . 37

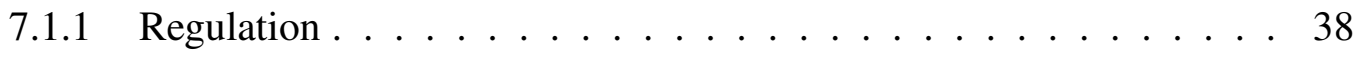

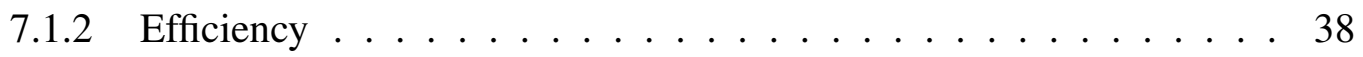

7.1 .3 Input Resistance . . . . . . . . . . . . . . . . . . . 41

7.2 Elliptical Machine to Converter Integration Tests _ . . . . . . . . . 43

7.3 Converter to Inverter Integration Tests $\ldots \ldots \ldots \ldots$

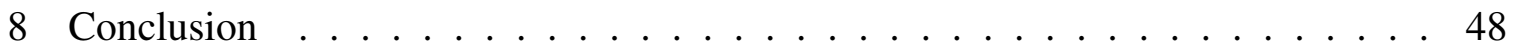

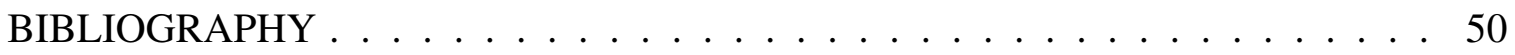

Appendix A Senior Project Analysis . . . . . . . . . . . . 53

A.1 Summary of Functional Requirements . . . . . . . . . . . . . 53

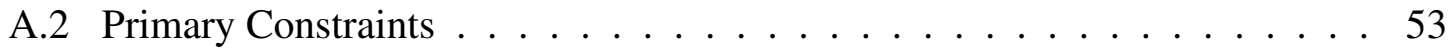

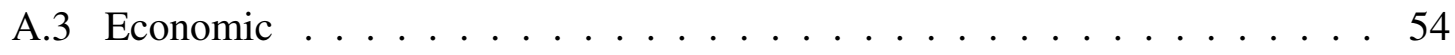

A.4 If manufactured on a commercial basis . . . . . . . . . . 55

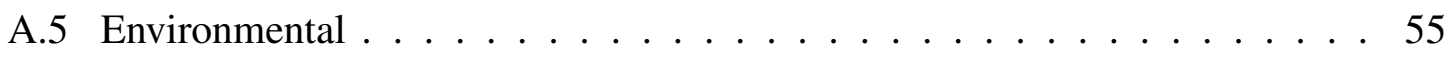

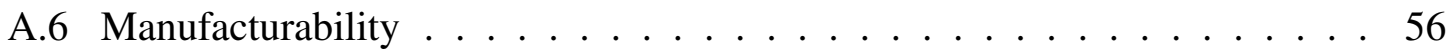

A.7 Sustainability $\ldots \ldots \ldots \ldots \ldots \ldots \ldots \ldots \ldots$

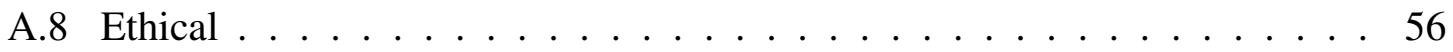


A.9 Health and Safety . . . . . . . . . . . . . . 57

A.10 Social and Political . . . . . . . . . . . . . . . 57

A.11 Development . . . . . . . . . . . . . . 58 


\section{LIST OF TABLES}

Table

Page

2.1 EHFEM buck-boost converter requirements and specifications . . . . . 6

2.2 Final PCB bill of materials . . . . . . . . . . . . . . . 11

2.3 Summary of Project Costs . . . . . . . . . . . . . . . . . . . . . 12

5.1 Metric evaluation plan . . . . . . . . . . . . . 25

5.2 Subthreshold current slopes . . . . . . . . . . . . . . . . . . 30

7.1 Burst mode test results . . . . . . . . . . . . . . . 39

$7.2 \mathrm{CCM}$ test results . . . . . . . . . . . . . . . . 40

7.3 Converter load and line regulation $\ldots \ldots \ldots 41$ 


\section{LIST OF FIGURES}

Figure

Page

2.1 Winter 2015 Gantt Chart . . . . . . . . . . . . . . . . 7

2.2 Spring 2015 Gantt Chart $\ldots \ldots \ldots \ldots$

2.3 Fall 2015 Gantt Chart . . . . . . . . . . . . . . . . . . . . . . 8

2.4 Winter 2016 Gantt Chart _. . . . . . . . . . . . . . . . . . 9

2.5 Spring 2016 Gantt Chart . . . . . . . . . . . . . . . 10

2.6 Summer 2016 Gantt Chart . . . . . . . . . . . . . . . . . . 10

3.1 Level 0 block diagram for EHFEM . . . . . . . . . . . . . . 13

3.2 Level 1 block diagram for the DC-DC converter . . . . . . . . . . . . 13

3.3 Output feedback on LT8705 chip [1] . . . . . . . . . . . . . . 14

3.4 Input feedback on LT8705 chip [1] . . . . . . . . . . . . . . 16

4.1 Simulation 1 circuit diagram . . . . . . . . . . . . . . 19

4.2 Iteration 1 output voltage, from $10 \mathrm{~V}$ to $50 \mathrm{~V}$ in steps of $10 \mathrm{~V} \ldots \ldots$

4.3 Iteration 2 Circuit Diagram . . . . . . . . . . . . . 21

4.4 Simulation 3 Circuit Diagram . . . . . . . . . . . . . . . . . . 22

4.5 Iteration 3 output voltage, from $6 \mathrm{~V}$ to $50 \mathrm{~V}$ in steps of $2 \mathrm{~V} \ldots \ldots 23$

4.6 Iteration 4 Circuit Diagram $\ldots \ldots \ldots \ldots$. . . . . . . . . . 24

5.1 MOSFET characterization test setup . . . . . . . . . . 26

5.2 Stress testing circuit . . . . . . . . . . . . . . . 27

5.3 Dimensions of largest power spike for $50 \mathrm{~V}$ input $\ldots \ldots \ldots$

5.4 LTspice waveform characteristics . . . . . . . . . . . . . 28

5.5 Drain-source subthreshold IV curves . . . . . . . . . . . . . . . . 29

5.6 Sub-threshold current characteristics . . . . . . . . . . . . . 30 
6.1 Rev 1 board . . . . . . . . . . . . . . . . . 32

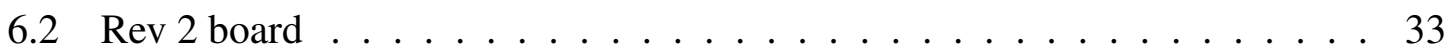

6.3 Effects of via in power path circuits . . . . . . . . . . 35

6.4 Rev 3 board . . . . . . . . . . . . . . . . 36

7.1 Test setup for converter operation . . . . . . . . . . . . 37

7.2 Burst mode efficiency for different load currents . . . . . . . . . . . . 41

7.3 CCM efficiency for different load currents . . . . . . . . . . . . 41

7.4 Converter IV curves in burst mode . . . . . . . . . . . . . . . . . 42

7.5 Converter IV curves in forced continous mode . . . . . . . . . . . . . . 42

7.6 Elliptical-converter operation test setup . . . . . . . . . . . . 43

7.7 Minimum SPM necessary to meet a constant current load . . . . . . . . . 44

7.8 Converter to Inverter Integration Test Setup _ . . . . . . . . . . . . . 44

7.9 Current from DC-DC converter to microinverter. This is the voltage waveform across a $1 m \Omega$ resistor. . . . . . . . . . . . . . . . . . . 46

7.10 Converter-inverter current using a makeshift differential probe. $V_{i n}=35 \mathrm{~V}$ with 3A current limit. . . . . . . . . . . . . . . . . . . 47

8.1 Proposed input protection circuit . . . . . . . . . . . . . . . . 49 


\section{Chapter 1: Introduction}

Any student in a STEM field is periodically reminded that the world is warming, the oceans are acidifying, sea level is rising, and that these effects will continue to worsen for the foreseeable future, barring a dramatic cultural shift. Moreover, any reforms must be successfully pitched to countries undergoing their industrial revolutions. To make matters worse, there exist powerful corporate entities with a vested interest in the status quo. [2]

A cultural shift is difficult to engineer, but it happens in baby steps. The best strategy is to incentivize eco-friendly attitudes by manipulating the cost-benefit structures behind everyday decisions. The Energy Harvesting from Exercise Machines (EHFEM) project does just that, by making it easy and fun to generate energy for the grid.

The EHFEM project seizes the potential power source in Cal Poly's REC center, which makes use of several Precor elliptical machines. These machines have a mechanism included that converts a portion of the user's energy output to power the indicating display. Excess energy, however, is dissipated across two $20 \Omega$ resistors. A running student can reliably generate up to $150 \mathrm{~W}$ [3], so most of the available energy becomes useless heat. The EHFEM project aims to preserve that energy in a useful form by equipping each machine with a grid-tied inverter.

A Florida-based company called ReRev employs a similar scheme, instead opting for a centralized inverter. Rhymebus, a Chinese based company, offers fully integrated exercise machines that claim " $80 \%$ electrical efficiency." EHFEM more closely resembles Green Revolution, which works with a company called Gyre9 to retrofit a set of exercise machines with a device to harvest power, deliver it to the grid, and display the results to the user. This project focuses on delivering $80 \%$ power efficiency over the DC input range from an elliptical machine. [4-6]

Professor Braun conceived of the EHFEM project at Cal Poly San Luis Obispo, and it has produced projects since 2007, starting with multidisciplinary teams that generated 
electrical power using exercise machines. Focus has since shifted to the electrical characteristics of the machine output, concerning DC-DC converters [7-9], input and output protection systems [10-12], and information display systems for workout progress [13, 14]. Martin Kou conducted an extensive characterization of the elliptical machine output and investigated multiple hard-switching topologies of DC-DC converters. Rickard and Stowe presented valuable information for the implementation of the LTC3780 controller, as well as the transfer of a circuit to a PCB. This project adds to a body of knowledge started by Alvin Hilario, who first presented a Four-Switch Buck-Boost solution for EHFEM in 2011. His solution used several chips from Linear Technology, including the LTC3780. The LT8705 based design in this thesis benefits from simplification to a single chip and a reduced $\mathrm{BOM}$ size and cost $[15,16]$.

This project produces a robust, efficient DC-DC converter with simplified installation and a lifetime greater than or equal to the lifetime of the exercise machine.

Thesis Statement This project demonstrates that the four-switch buck-boost DC-DC converter topology is appropriate for interfacing with the electrical grid. It converts a challenging input range of 5-60 V to a stable $36 \mathrm{~V}$. In addition, the current output of the elliptical machine reaches up to $7 \mathrm{~A}$. This DC-DC converter should be able to handle for brief periods the high power associated with this current. This thesis studies the capability of a four-switch buck-boost converter to meet input resistance and regulation requirements and to maximize the efficiency of the EHFEM system.

This report is organized chronologically, with early chapters devoted to project planning and functional decomposition. Chapters 4 and 5 discuss the design work done before assembling a complete board. Chapter 6 documents the PCB design process.

EHFEM's problem definition is denoted in the name, and this project presents a simple plan to address that problem. 


\section{Chapter 2: Project Planning}

The first two sections of this chapter discuss the values and considerations that informed design decisions. With requirements and specifications recorded, the next section provides project timelines, separated for each quarter. The last section discusses project costs and their classifications.

\subsection{Customer Needs Assessment}

This section discusses customer needs in broad, non-technical terms. This description informs the requirements and specifications detailed in Section 2.2.

The EHFEM project addresses environmental concerns without compromising practical, fiscal responsibility. Institutions have an image to maintain, and environmental stewardship is chic, but many believe that it fails to financially justify itself. The EHFEM project must pay for itself over a reasonable period.

To help ease the transition from a regular elliptical machine to an EHFEM-altered machine, the alterations must not change the user experience associated with the device.

As always, consumer safety remains a critical concern. Because this project modifies a consumer product, it must not compromise the safety of that product.

The next section translates the customer needs defined in this section into verifiable specifications that this project can implement.

\subsection{Requirements and Specifications}

This section refines the customer needs defined in Section 2.1 into technical terms. The specifications are defined such that fulfilling them adequately fulfills customer needs.

EHFEM address environmental concerns by converting excess energy, generated in exercise on an elliptical machine, to usable power for the grid. The elliptical machine produces a DC voltage, so an inverter would provide this functionality, but the available 
microinverter has an efficiency "sweet spot" at $36 \mathrm{~V} \pm 1 \mathrm{~V}$ [15]. This thesis addresses that disconnect by introducing a DC-DC converter that can reliably meet the sweet spot. In addition, the sum of load and line regulation of the DC-DC converter must not exceed $1 / 36=2.78 \%$. Line regulation comes from output voltages produced from input voltages at $10 \mathrm{~V}$ and $60 \mathrm{~V}$ at $1 \mathrm{~A}$ load current. Load regulation is calculated with $V_{i n}=35 \mathrm{~V}$ at load currents of $1 \mathrm{~A}$ and $4 \mathrm{~A}$.

EHFEM promises fiscally responsibility. The EHFEM project has defined a maximum price for the system alterations. For the project to pay itself off within 10 years, each modification must cost less than $\$ 360$. [15] This is calculated using conservative estimates for elliptical machine usage, workout intensity, system efficiency, and the price of electricity over the next few years. The $\$ 360$ figure also encompasses installation costs, which may constitute a large portion of the total alteration cost.

To meet cost requirements, the DC-DC converter must have an efficiency greater than $80 \%$. Additionally, the peak efficiency should occur at input voltages around $25.7 \mathrm{~V}$, called $V_{\text {nominal }}$. This comes from the average output voltage seen at all input resistances in Martin Kou's thesis [7].

To minimize costs, the EHFEM system incorporates microinverters, intended for use with a solar panel. This thesis specifies the Enphase M215 for its ideal startup time [17]. The M215 reaches maximum efficiency at $36 V_{i n}$, and the elliptical output ranges from $10 \mathrm{~V}$ to $60 \mathrm{~V}$. A DC-DC converter must consistently buck voltages up to $60 \mathrm{~V}$ and boost voltages as low as $10 \mathrm{~V}$ to meet $36 \mathrm{~V}$.

The M215 also specifies a max input current of 7 A [18]. The DC-DC converter must not supply currents above $7 \mathrm{~A}$. This means the DC-DC converter must have an input current limit of $36 \mathrm{~V} \times 7 \mathrm{~A} / \mathrm{V}_{\text {in }}, 4.2 \mathrm{~A}$ at $V_{\text {in }}=60 \mathrm{~V}$.

The EHFEM alterations must not alter the user experience of the elliptical machine. The running resistance must not change. Functionally, this means that the DC-DC converter must have an equivalent input resistance to the components it replaces. The elliptical comes 
with two 20 Sresistors in parallel, so the input resistance of the DC-DC converter must be $10 \Omega$.

Additionally, the alterations must not crowd the gym. They must minimize external cabling for safety and for user experience. The DC-DC converter and microinverter must fit within the confines of the elliptical machine body.

Alterations must not compromise the safety of the elliptical machine. Also, the alterations must not cause the elliptical machine to fall out of compliance with the various safety standards from NEC, UL, RoHS, or IEEE.

These marketing requirements are summarized below. The specifications listed in Table 2.1 derive directly from these requirements.

1. Delivers unused power to the grid.

2. Complies with NEC, UL, RoHS, and IEEE 1547 standards.

3. No net cost to Cal Poly over the lifespan of the elliptical.

4. Does not alter the user experience associated with the elliptical.

5. Must work with the M215 Microinverter.

6. Must not compromise the safety of the elliptical machine.

With requirements and specifications enumerated, the next section can detail the project timeline.

\subsection{Timeline}

This section discusses the planning goals and challenges throughout the project lifetime. It breaks down each quarter individually with Gantt charts.

Work began in Winter 2015, two quarters before the next scheduled round of the Power Electronics series. Without theoretical grounding, research was principally done by studying the senior project and thesis reports of previous EHFEM students. They provided a 
Table 2.1: EHFEM buck-boost converter requirements and specifications

\begin{tabular}{|c|c|c|}
\hline $\begin{array}{l}\text { Marketing } \\
\text { Requirements }\end{array}$ & Engineering Specifications & Justification \\
\hline 1,5 & $\begin{array}{l}\text { Converts input range of } 10-60 \mathrm{~V} \\
\text { to } 36 \mathrm{~V} \text { output. }\end{array}$ & $\begin{array}{l}\text { Users do not exercise at a con- } \\
\text { sistent rate, so any voltage gener- } \\
\text { ated corrects to the microinverters } \\
\text { voltage sweet spot. }\end{array}$ \\
\hline 1,5 & $\begin{array}{l}\text { Sum of line and load regulation } \\
\text { does not exceed } 2.78 \%\end{array}$ & $\begin{array}{l}\text { This is the maximum allow- } \\
\text { able regulation to remain with } \\
{[35 \mathrm{~V}, 37 \mathrm{~V}]}\end{array}$ \\
\hline 4 & $\begin{array}{l}\text { Input impedance equals } 10 \Omega \pm \\
1 \Omega \text {. }\end{array}$ & $\begin{array}{l}\text { The input impedance of the } \\
\text { converter needs to match the } \\
\text { impedance of the resistors it will } \\
\text { replace so it doesn't alter the ellip- } \\
\text { tical machine's circuit topology. }\end{array}$ \\
\hline 1,3 & $\begin{array}{l}\text { Operates with } 80 \% \text { efficiency or } \\
\text { greater over the specified input } \\
\text { range. }\end{array}$ & $\begin{array}{l}\text { System harvests maximum energy } \\
\text { to justify the upfront cost of the } \\
\text { inverter and materials. }\end{array}$ \\
\hline 1 & $\begin{array}{l}\text { Efficiency maximum should oc- } \\
\text { cur at input voltages of } 25.7 \mathrm{~V} \text {. }\end{array}$ & $\begin{array}{l}25.7 \mathrm{~V} \text { is the expected output volt- } \\
\text { age of the elliptical machine. }\end{array}$ \\
\hline 5 & $\begin{array}{l}\text { DC-DC converter output current } \\
\text { must not exceed } 7 \mathrm{~A} \text {. }\end{array}$ & $\begin{array}{l}\text { The M215 datasheet specifies this } \\
\text { current limit for its input. }\end{array}$ \\
\hline 6,4 & $\begin{array}{l}\text { Apparatus must fit within the al- } \\
\text { ready existing shell of the ellipti- } \\
\text { cal machine. }\end{array}$ & $\begin{array}{l}\text { A separate converter box would } \\
\text { crowd the gym }\end{array}$ \\
\hline 3 & $\begin{array}{l}\text { Materials and installation costs } \\
\text { must not exceed } \$ 360 \text {. }\end{array}$ & $\begin{array}{l}\text { Cal Poly does not want to lose } \\
\text { money modifying gym equip- } \\
\text { ment. The electricity generated } \\
\text { over the lifetime of the elliptical } \\
\text { machine costs } \$ 360 \text {. }\end{array}$ \\
\hline 2 & $\begin{array}{l}\text { Must comply with NEC, UL, } \\
\text { RoHS, and IEEE } 1547 \text { standards. }\end{array}$ & $\begin{array}{l}\text { Standard compliance ensures } \\
\text { safety and environmental respon- } \\
\text { sibility. }\end{array}$ \\
\hline 3 & $\begin{array}{l}\text { Connectors should use spade lugs } \\
\text { to connect to the elliptical and ba- } \\
\text { nana plugs to connect to the DC- } \\
\text { DC converter. }\end{array}$ & $\begin{array}{l}\text { Installation must be quick and } \\
\text { easy, and familiar connectors en- } \\
\text { sure that. }\end{array}$ \\
\hline
\end{tabular}


comparison for component calculations and hardware characterizations. Figure 2.1 maps this progress.

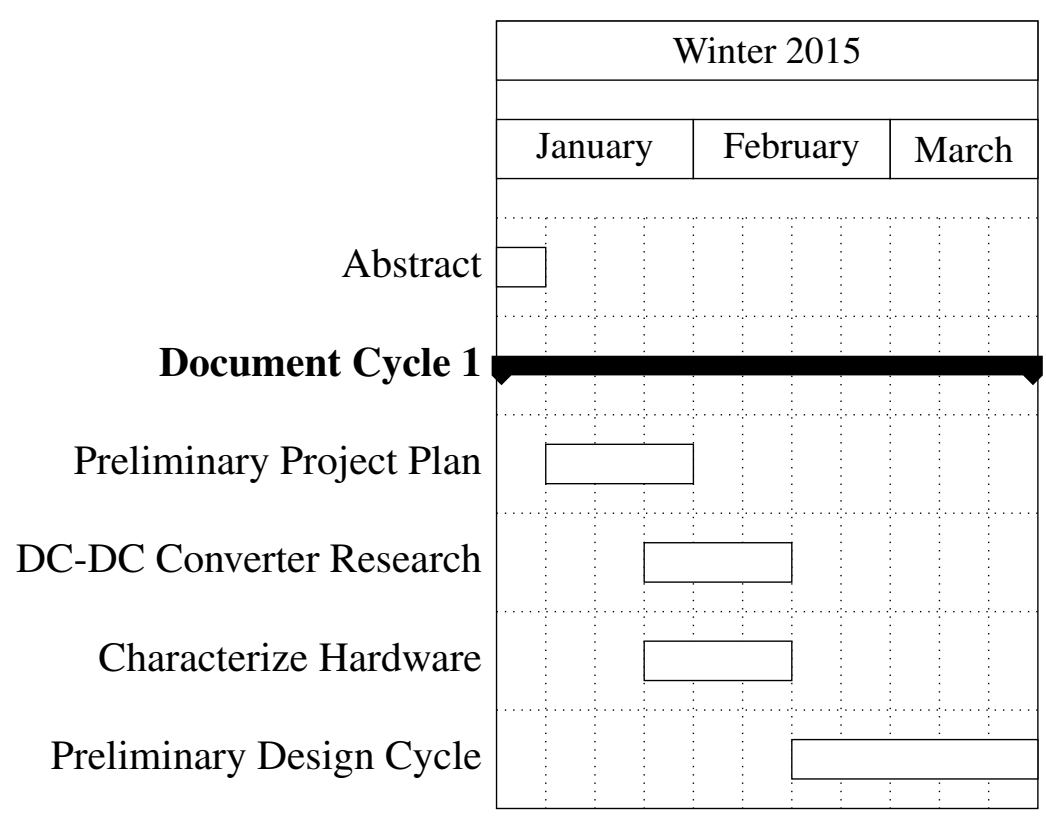

Figure 2.1: Winter 2015 Gantt Chart

Spring of 2015 was spent simulating the circuit. Each simulation got its own recalculation of component values and took between ten minutes and two hours, depending on accuracy. By the end of the quarter, the simulation fulfilled functional requirement number 1, the buck-boost functionality of the circuit.

Several attempts to reinvent the wheel incurred delay. By ignoring the test circuit and constructing the simulation from examples from research papers, a problem arose in the orientation of one of the MOSFETs. MOSFETs connected to the converter input and output need to have their sources tied to the inductor. Until late in the quarter, simulations failed with the output MOSFET source tied to the output.

In the summer of 2015, I had the good fortune of working at One Cycle Control, a small power electronics company, where I designed, assembled and fabricated a PCB for the first time. I came back to school very excited to apply my experience to the next phase of the project: the physical realization.

Ryan Matteo joined EHFEM in the 2015 to 2016 school year. His senior project was 


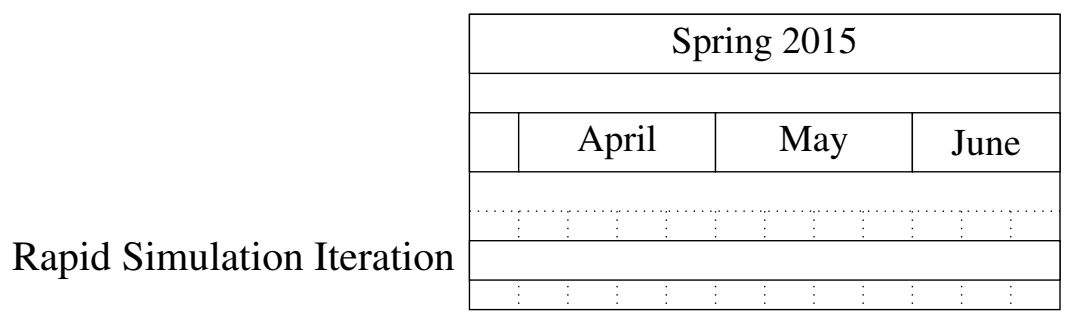

Figure 2.2: Spring 2015 Gantt Chart

laid out and fabricated a 4-Switch Buck-Boost Converter. This became a useful project synergy. It freed me up for a phase of MOSFET testing.

Figures 2.3 and 2.4 show the proposed plan for the PCB design and implementation. The design stage, however, took much longer than expected, and these two quarters were spent laying out several iterations of a board.

MOSFET selection is crucial to this project. The high currents and the hard switching topology can damage a MOSFET that cannot dissipate the heat fast enough. Additionally, a large power spike might break a component within milliseconds of startup if it exceeds the component's maximum pulse energy.

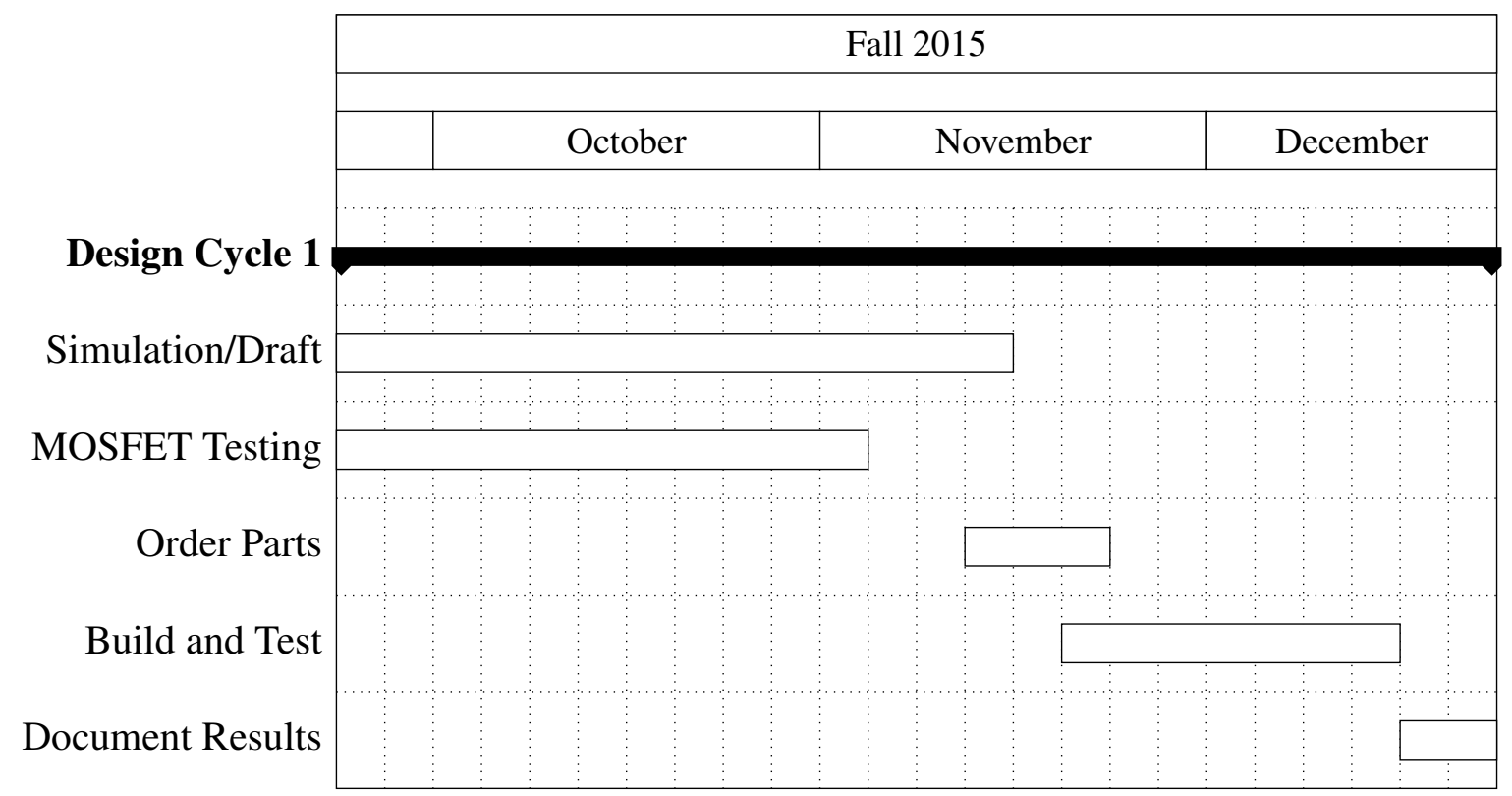

Figure 2.3: Fall 2015 Gantt Chart

The Spring of 2016 was similarly impacted. Figure 2.5 shows the proposed plan for 


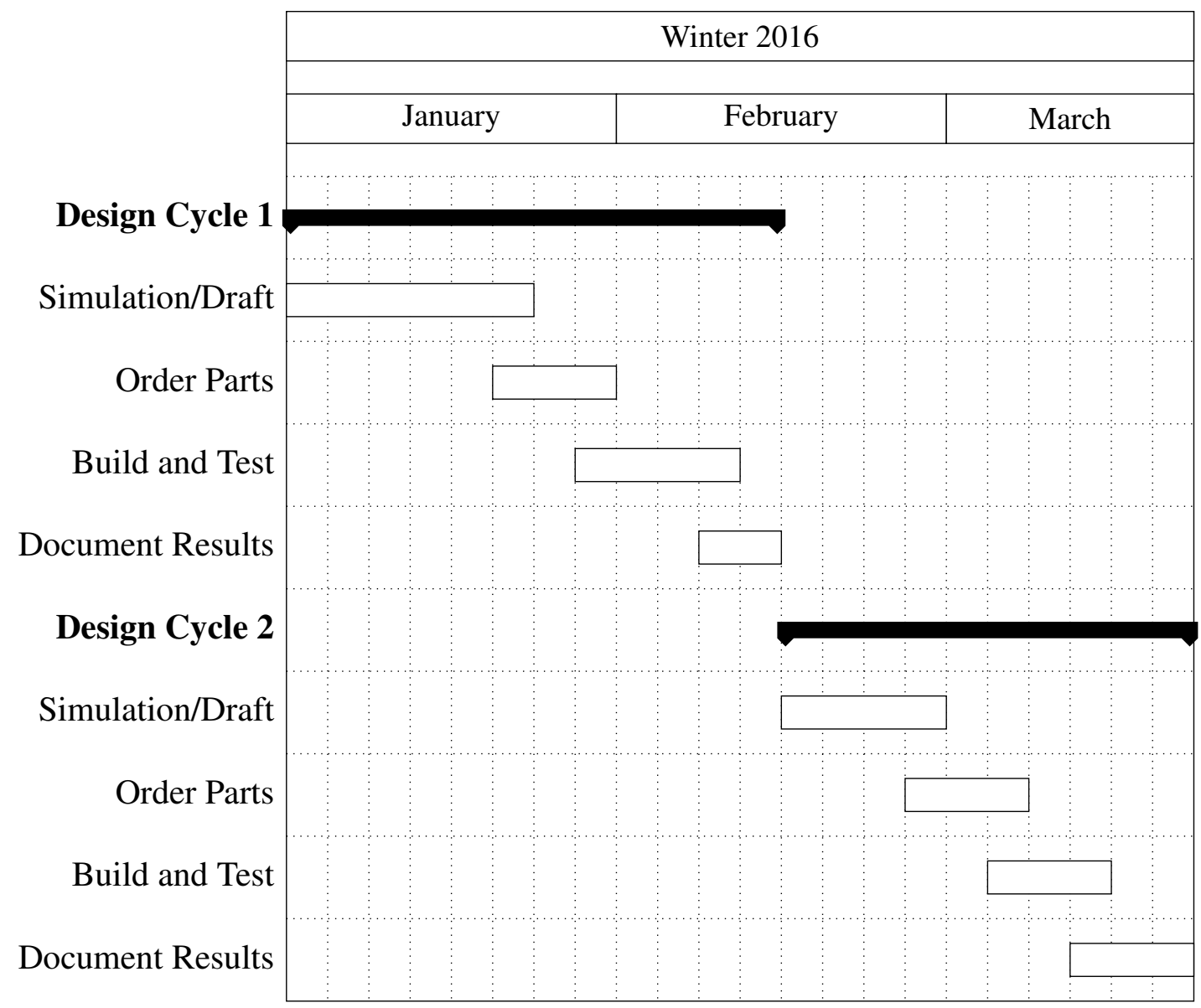

Figure 2.4: Winter 2016 Gantt Chart

the quarter. However, the first physical implementation was fabricated near the end of the quarter and hastily assembled. Unfortunately, testing and evaluation yielded no results before the end of the quarter when Ryan, the project lead, graduated.

In the summer of 2016, I consulted with Joshua Quintero, a Field Applications Engineer at Linear Technology, who graciously provided a demo board and several pointers on the use of the LT8705 chip. With renewed vigor, I set about the next iteration of the DC-DC converter.

This effort was secondary, however, to a full time summer job, so assembly and test were not conducted until the beginning of the Fall 2016 quarter. 


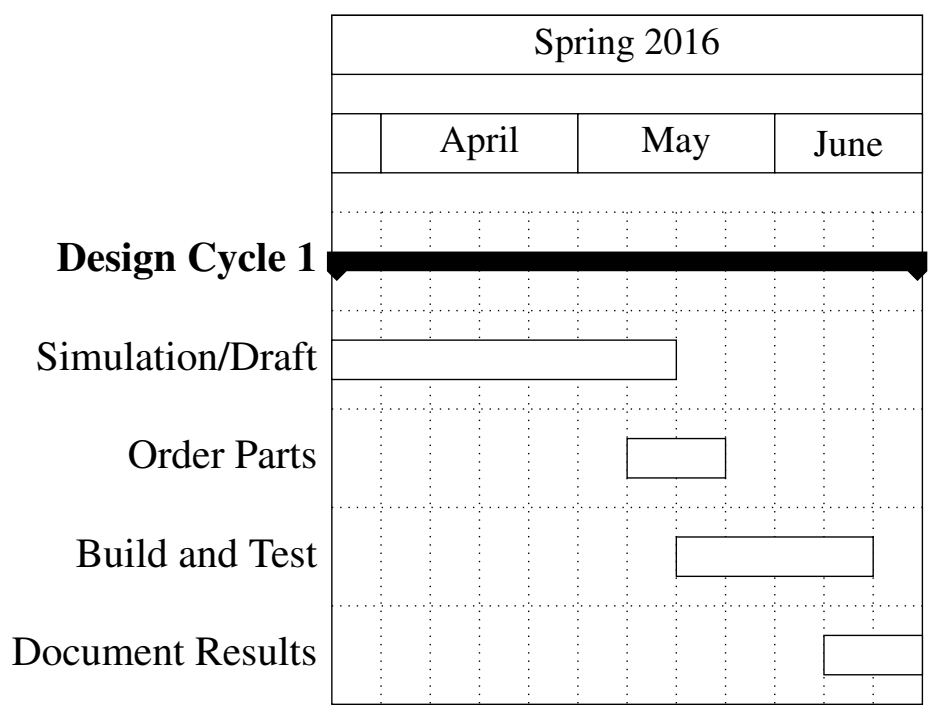

Figure 2.5: Spring 2016 Gantt Chart

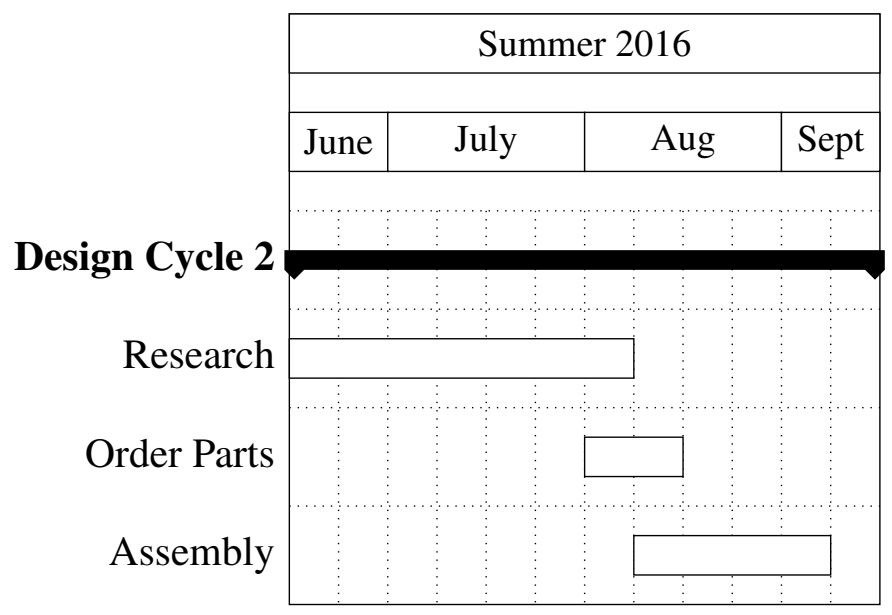

Figure 2.6: Summer 2016 Gantt Chart

\subsection{Project Costs}

This section discusses project costs. They fall into three categories: parts, PCB fabrication, and labor.

Table 2.2 shows a breakdown of the parts cost per PCB. Prices are listed for groups of ten, taking advantage of bulk pricing. About $73 \%$ of the materials cost comes from the MOSFETs, the LT8705 controller, and the high voltage ceramic capacitors on the input. Because this project sourced parts for five PCBs, the materials cost increases by a factor of 5. 
Large scale PCB fabrication reduces the marginal cost of fabrication. This means that the materials cost total shown in Table 2.2, \$39.71, is the absolute minimum cost for each DC-DC converter.

Table 2.2: Final PCB bill of materials

\begin{tabular}{lrcc}
\hline Designator & Quantity & Price & Extended Price \\
\hline C1 & 1 & $\$ 0.07$ & $\$ 0.07$ \\
C2 & 1 & $\$ 0.05$ & $\$ 0.05$ \\
C3 & 1 & $\$ 0.04$ & $\$ 0.04$ \\
C4,C5 & 2 & $\$ 0.04$ & $\$ 0.09$ \\
C6,C7 & 2 & $\$ 0.04$ & $\$ 0.08$ \\
C8,C9 & 2 & $\$ 0.05$ & $\$ 0.10$ \\
C10,C11,C14,C15 & 4 & $\$ 0.47$ & $\$ 1.88$ \\
C12,C13,C16,C17, C18,C19,C20,C21 & 8 & $\$ 1.29$ & $\$ 10.32$ \\
D1,D2 & 2 & $\$ 0.15$ & $\$ 0.30$ \\
P1 & 1 & $\$ 0.07$ & $\$ 0.07$ \\
P2,P3 & 2 & $\$ 0.05$ & $\$ 0.09$ \\
P4 & 1 & $\$ 0.02$ & $\$ 0.02$ \\
P5,P6,P7,P8 & 4 & $\$ 0.56$ & $\$ 2.22$ \\
Q1,Q2,Q3,Q4,Q5,Q6 & 6 & $\$ 1.67$ & $\$ 10.02$ \\
R1 & 1 & $\$ 0.01$ & $\$ 0.01$ \\
R2,R4 & 2 & $\$ 0.01$ & $\$ 0.01$ \\
R3 & 1 & $\$ 0.01$ & $\$ 0.01$ \\
R5 & 1 & $\$ 0.01$ & $\$ 0.01$ \\
R6 & 1 & $\$ 0.01$ & $\$ 0.01$ \\
R7 & 1 & $\$ 0.01$ & $\$ 0.01$ \\
R8 & 1 & $\$ 0.01$ & $\$ 0.01$ \\
R9,R10 & 2 & $\$ 0.01$ & $\$ 0.01$ \\
U1 & 1 & $\$ 8.50$ & $\$ 8.50$ \\
W1,W2,W3,W4 & 4 & $\$ 0.02$ & $\$ 0.10$ \\
R12,R13,R14,R15, R16,R17 & 6 & $\$ 0.01$ & $\$ 0.05$ \\
R11 & 1 & $\$ 0.97$ & $\$ 0.97$ \\
C22 & $\$ 0.05$ & $\$ 0.05$ \\
C23 & 1 & $\$ 0.04$ & $\$ 0.04$ \\
L1 & $\$ 4.42$ & $\$ 4.42$ \\
Header Jumpers & $\$ 0.09$ & $\$ 0.18$ \\
\hline Total & & & $\$ 39.71$ \\
\hline
\end{tabular}

Sierra Circuits fabricated the boards using their automated NoTouch service. For 5 boards, the total cost came out to $\$ 263.42, \$ 52.68$ per board. This brings the total cost of 
each PCB to $\$ 92.39$.

Using an estimated 420 hours of project time and an hourly rate of $\$ 56.25$, labor costs $\$ 23,625$. Table 2.3 contains a summary of the project costs for each category and a total.

Table 2.3: Summary of Project Costs

\begin{tabular}{ll}
\hline Item & Cost Estimate \\
\hline Circuit Components & $\$ 198.55$ \\
PCB Fabrication & $\$ 263.42$ \\
Labor & $\$ 23,625.00$ \\
\hline Total & $\$ 24,086.97$ \\
\hline
\end{tabular}

With the project definition and planning out of the way, this report moves on to technical logistics. 


\section{Chapter 3: Functional Decomposition}

This chapter provides a high level examination of the design, as well as the reasoning behind some early design choices.

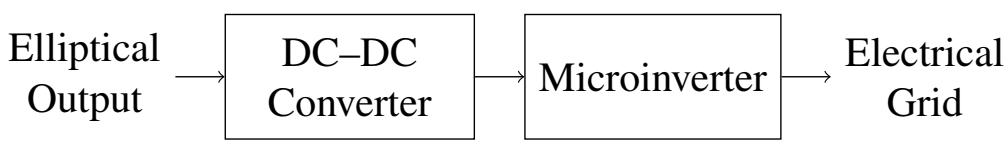

Figure 3.1: Level 0 block diagram for EHFEM

The Precor elliptical machine converts the user's mechanical energy to a voltage, up to $60 \mathrm{~V}$. The DC-DC converter standardizes the voltage to a $36 \mathrm{~V}$ "sweet spot," to maximize the efficiency for the M215 microinverter, which sends the energy to the electrical grid.

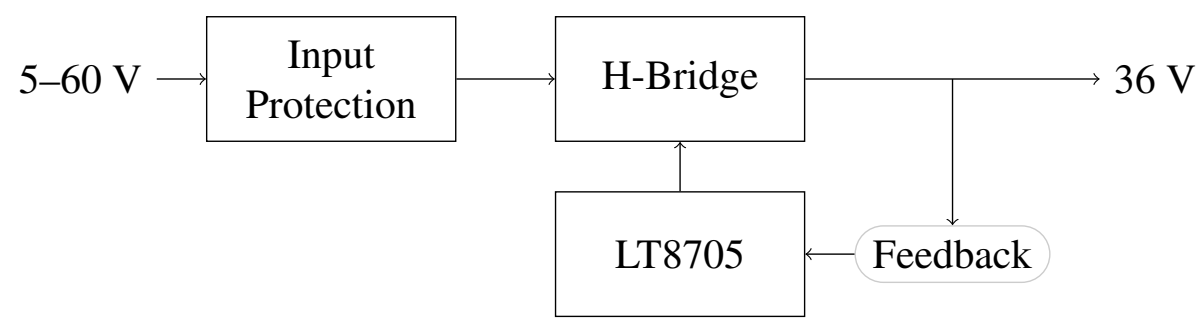

Figure 3.2: Level 1 block diagram for the DC-DC converter

The Buck-Boost Converter follows a four switch topology, controlled by the LT8705 controller IC. The input protection eliminates any wayward spikes in voltage from the elliptical machines output.

Before going any further, the next section shows the reasoning behind the topology and controller chip selection.

\subsection{Choosing the Topology and Controller}

The Four-Switch Buck-Boost topology was chosen for its ability to Buck and Boost without inverting the output. It also has an advantage over an analogous isolated topology: a flyback converter. A flyback converter would require a large transformer with high inductive 


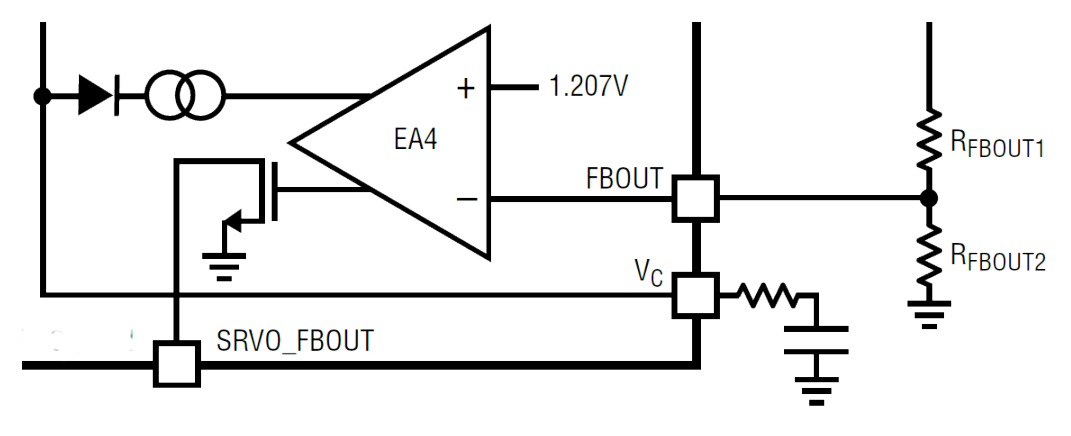

Figure 3.3: Output feedback on LT8705 chip [1]

currents.

Additionally, Professor Taufik recommended Four-Switch Buck-Boost topology for applications below $125 \mathrm{~W}$. For EHFEM purposes, the converter likely spends more time boosting than bucking, and acts in a lower power environment. Martin Kou used similar reasoning in his thesis [7].

The LT8705 produces signals for a four-switch buck-boost converter with appropriate current delivering capability. Additionally, it claims efficiencies greater than $90 \%$, well over the efficiency specification of this project. For these reasons, the LT8705 was selected for use in this design.

The next section shows the feedback calculations for the input and output of the converter. It unravels the black box for the "feedback" block in Figure 3.2.

\subsection{Feedback Calculations}

Figure 3.3 illustrates the "Feedback" node shown in Figure 3.2. The resistive divider matches the internally generated $1.207 \mathrm{~V}$ reference when the output reaches $36 \mathrm{~V}$. 


$$
\begin{aligned}
1.207 & =36 \frac{R_{F B O U T 2}}{R_{F B O U T 1}+R_{F B O U T 2}} \\
\frac{36}{1.207} & =\frac{R_{F B O U T 1}+R_{F B O U T 2}}{R_{F B O U T 2}} \\
\frac{R_{F B O U T 1}}{R_{F B O U T 2}} & =\frac{36}{1.207}-1 \approx 28.83
\end{aligned}
$$

Using an online resistor calculator, this ratio translates to an ideal set of E12 series resistors. Choosing standard values makes it easier and cheaper to source components, and using a resistor calculator ensures accuracy in the ratio while minimizing the number of components [19].

$$
\begin{aligned}
& R_{F B O U T 1}=270 k \Omega \\
& R_{F B O U T 2}=10 k \Omega \| 150 k \Omega
\end{aligned}
$$

A similar strategy was used for the input feedback pin, with laxer requirements. Figure 3.4 shows the input feedback node. The chip needed only to shut down at input voltages somewhere between $5 \mathrm{~V}$ and $10 \mathrm{~V}$. I chose $6 \mathrm{~V}$, but wasn't overly attached to it. The benefits of cheap and easily available components outweighed precision in this case.

$$
\begin{aligned}
& \frac{R_{S H D N 1}}{R_{S H D N 2}}=\frac{6}{1.234}-1 \approx 3.862 \\
& R_{S H D N 1}=150 \mathrm{k} \Omega \\
& R_{S H D N 2}=39 \mathrm{k} \Omega
\end{aligned}
$$

With the feedback calculations handled, the next section discusses MOSFET selection based on efficiency requirements. 


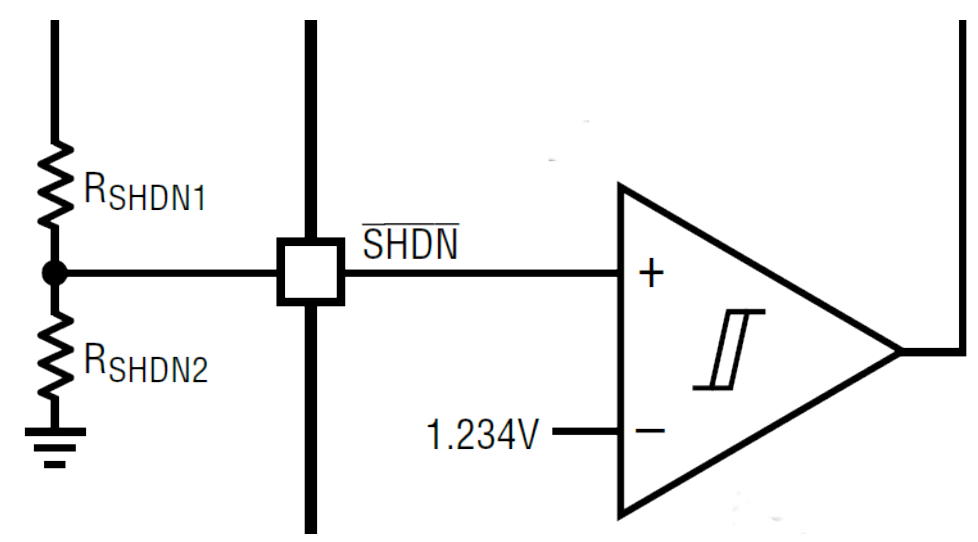

Figure 3.4: Input feedback on LT8705 chip [1]

\subsection{Switching vs. Conduction Losses}

This section evaluates MOSFETs for efficiency. MOSFET power losses consist of switching loss, the power lost charging and discharging the gate, and conduction loss, the power lost across the on resistance of the MOSFET. Equations 3.9 and 3.10 describe these losses.

$$
\begin{aligned}
P_{s w} & =C_{\text {gate }} V^{2} f=Q_{\text {gate }} V f \\
P_{\text {cond }} & =\frac{3}{2}{\overline{I_{L}}}^{2} R_{D S, \text { on }}
\end{aligned}
$$

Power MOSFETs trade off between gate capacitance and on resistance. Because this converter has consistent current and voltage conditions, this analysis focuses on the growth rates of switching and conduction loss with respect to gate capacitance and on resistance.

Equation 3.13 shows the sum of conduction and switching losses. Equations 3.11 and 3.12 show the partial differentials. From simulation, the gate-source voltage $V_{g s}$ is $6.78 \mathrm{~V}$. The frequency is set at $200 \mathrm{kHz}$. From the operating conditions discussed in the problem definition, the maximum average inductor current comes from boost mode: $I_{L}=\frac{215 \mathrm{~W}}{36 \mathrm{~V}} \frac{36 \mathrm{~V}}{10 \mathrm{~V}}=21.5 \mathrm{~A}$. For the numerical calculation, $C_{\text {gate }}$ is measured in $\mathrm{nC}$ and $R_{D S, \text { on }}$ is measured in $m \Omega$. 


$$
\begin{aligned}
\frac{\partial P_{\text {loss }}}{\partial C_{\text {gate }}} & =V^{2} f \\
\frac{\partial P_{\text {loss }}}{\partial R_{D S, \text { on }}} & =\frac{3}{2}{\overline{I_{L}}}^{2} \\
P_{\text {loss }} & =C_{\text {gate }} V^{2} f+\frac{3}{2}{\overline{I_{L}}}^{2} R_{D S, \text { on }} \\
& =\left(9.19 \times 10^{-3}\right) C_{\text {gate }}+\left(693.38 \times 10^{-3}\right) R_{D S, \text { on }}
\end{aligned}
$$

The total loss thus grows much faster with input resistance than it does with gate capacitance. For the FDMS86255, the switching loss comes to $377 \mathrm{~mW}$ and the conduction loss comes to $693 \mathrm{~mW}$. These losses would equal each other if the input current is $12.94 \mathrm{~A}$, which occurs at an input voltage of $16.6 \mathrm{~V}$.

However, the chosen MOSFET must have adequately small rise time to support the low duty cycles for extreme cases. As seen in the Simulations chapter, some pulses take less than $20 \mathrm{~ns}$ to occur. The rise time of the FDMS86255 is $10 \mathrm{~ns}$, so the FDMS86255 meets this requirement. 


\section{Chapter 4: Circuit Design and Simulation}

The rapid iteration and turnaround time of simulation makes it ideal for prototyping and debugging, at no extra cost. The LT8705 integrated circuit was designed by Linear Tech-

nology, which means the circuit simulation software of choice is LTSpice. [20] The goal of simulation is to arrive at a design for a DC-DC Converter with the following specifications:

1. $V_{\text {in }} \in[10,60] V$

2. $V_{\text {out }}=36 \mathrm{~V}$

3. $\Delta V_{\text {out }}=1 \mathrm{~V}$

4. $\hat{I}_{\text {out }}=7 \mathrm{~A}$

5. $\eta \geq 90 \%$

These goals come directly from the specifications listed in Table 2.1. The specifications, however, were uncertain until Iteration 3, meaning the component values were calculated multiple times with different targets in mind.

The following sections document the progression of functionality within the simulations. The next sections discuss the first simulations, in which the goal was to fulfill requirement 1 , the voltage regulation of the circuit. Section 4.3 shows the accomplishment of this goal.

\subsection{Iteration 1}

This section shows the initial challenges faced in simulations. The goal of this circuit was to achieve a functional buck-boost converter.

The preliminary circuit was a simplified version of the test circuit, provided by Linear Technology [21]. Figure 4.1 shows the circuit diagram. The main feedback loop was 
altered to produce the correct output voltage, $36 \mathrm{~V}$. The soft start capacitance was set higher to produce more realistic currents in the inductor. The biasing on the SHDN pin was lowered to $1.234 \times \frac{39+150}{39}=5.98$ (the calculation appears in section 3.2) The test circuit had small series resistances (R1 and R2 in the test circuit from [21]), incorrectly interpreted as parasitic components. These base resistances slowed the ON-OFF transitions and prevented ringing. Additionally, small RC filters from each end of the sense resistor to the chip were removed for simplicity. The sense resistance $1 \Omega$ was chosen randomly, supposing that it would only affect the degree of performance and not the baseline functionality.

The LT8705 uses an operating frequency between $100 \mathrm{kHz}$ and $400 \mathrm{kHz}$. The LT8705 datasheet states the efficiency/component size trade-off for frequency selection. EHFEM values both of these qualities, but efficiency most of all. This project chooses an operating frequency of $200 \mathrm{kHz}$ to account for both but favor efficiency.

The first successful iteration would serve as a baseline performance record, from which modifications could be made to mold the circuit slowly.

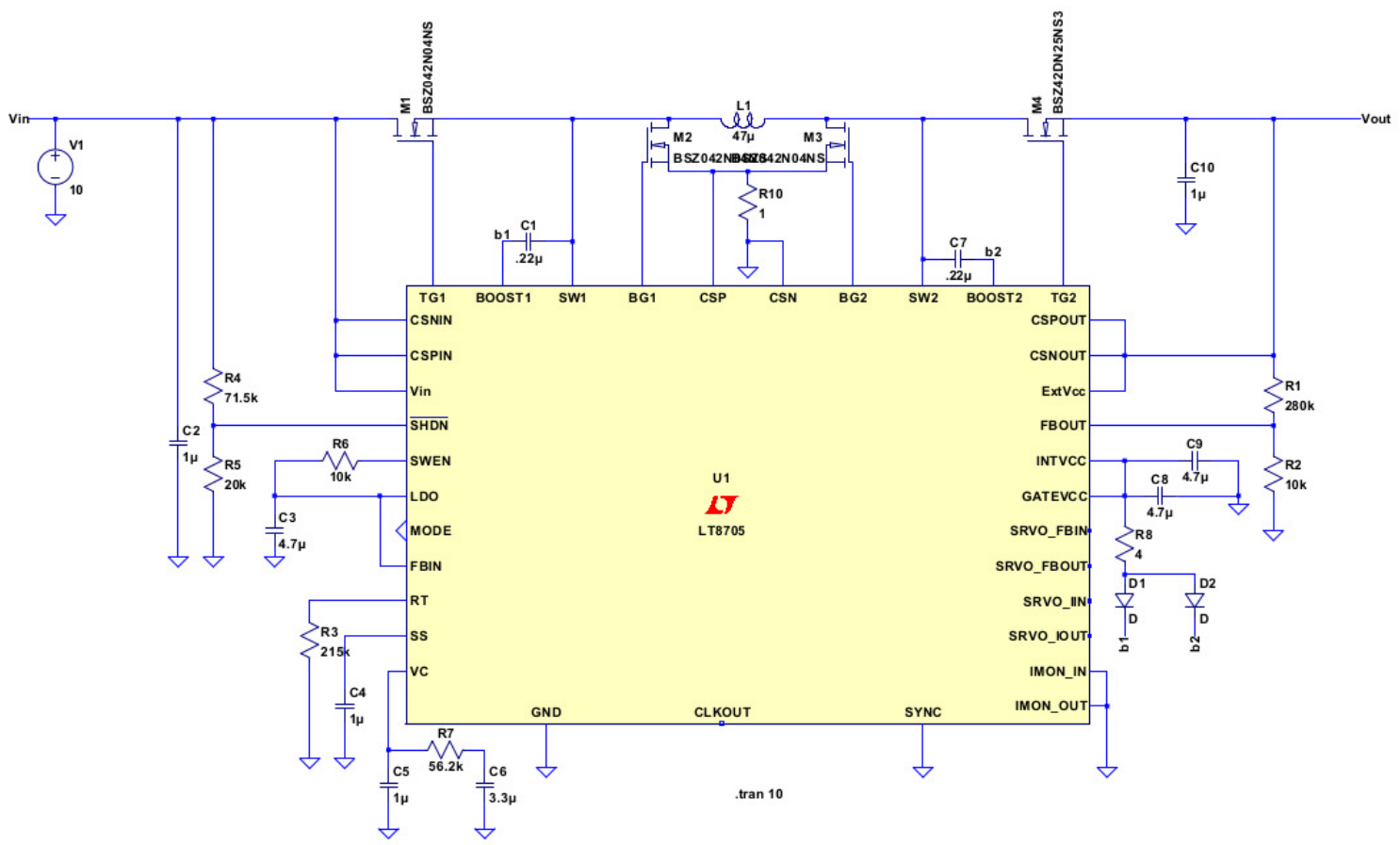

Figure 4.1: Simulation 1 circuit diagram 
To test this, the converter was simulated at several input voltages, above and below $V_{\text {out }}$. A successful result would present as $V_{\text {out }}$ reaching $36 \mathrm{~V}$ at all input voltages.

The first iteration failed to produce any usable results, however. The output voltage at steady state was linearly related to input voltage, meaning the feedback was serving no purpose. Figure 4.2 shows the results of several runs of the converter at different inputs. They indicate that the output voltage was simply the input voltage minus 4 to $6 \mathrm{~V}$.

After taking the power electronics course, I recognized that this resulted from the high sense resistance, randomly chosen. At high inductor current, switching shuts off and passes the input through. A high sense resistance causes the LT8705 to falsely sense an overcurrent state.

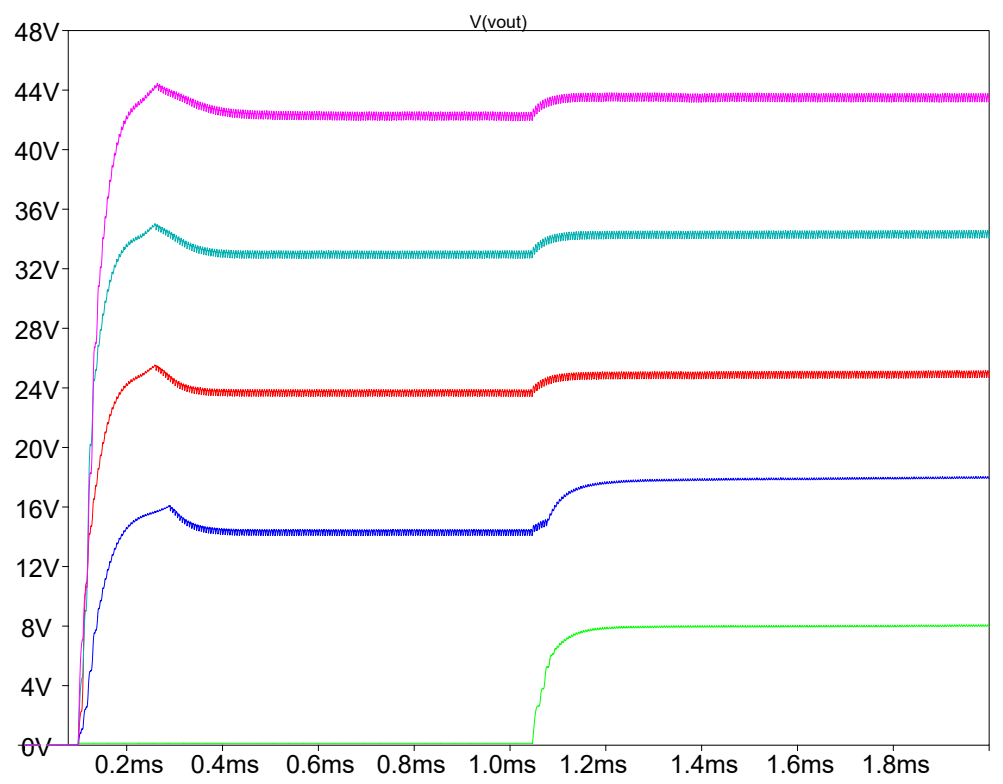

Figure 4.2: Iteration 1 output voltage, from $10 \mathrm{~V}$ to $50 \mathrm{~V}$ in steps of $10 \mathrm{~V}$

\subsection{Iteration 2}

This section regards further attempts to produce the core functionality of the converter.

This iteration saw the creation of an Excel file with the component calculation formulas written out. Using this file, the user can alter input and performance parameters and get the new component values instantly. The new component values came from this file. Note, 
at the time of these simulations, I still hadn't taken the power electronics series of classes. The component calculation formulas came from the LT8705 datasheet. I therefore failed to recognize the theoretical consequences of these component changes.

The new circuit, shown in Figure 4.3, came from calculations made under the assumption that the output voltage could be anywhere between $30 \mathrm{~V}$ and $36 \mathrm{~V}$, and a mistaken interpretation of the results. Therefore, the sense resistor value was still incorrect at $25 \mathrm{~m} \Omega$.

The goal of this simulation remained the same: to produce a functional buck-boost converter.

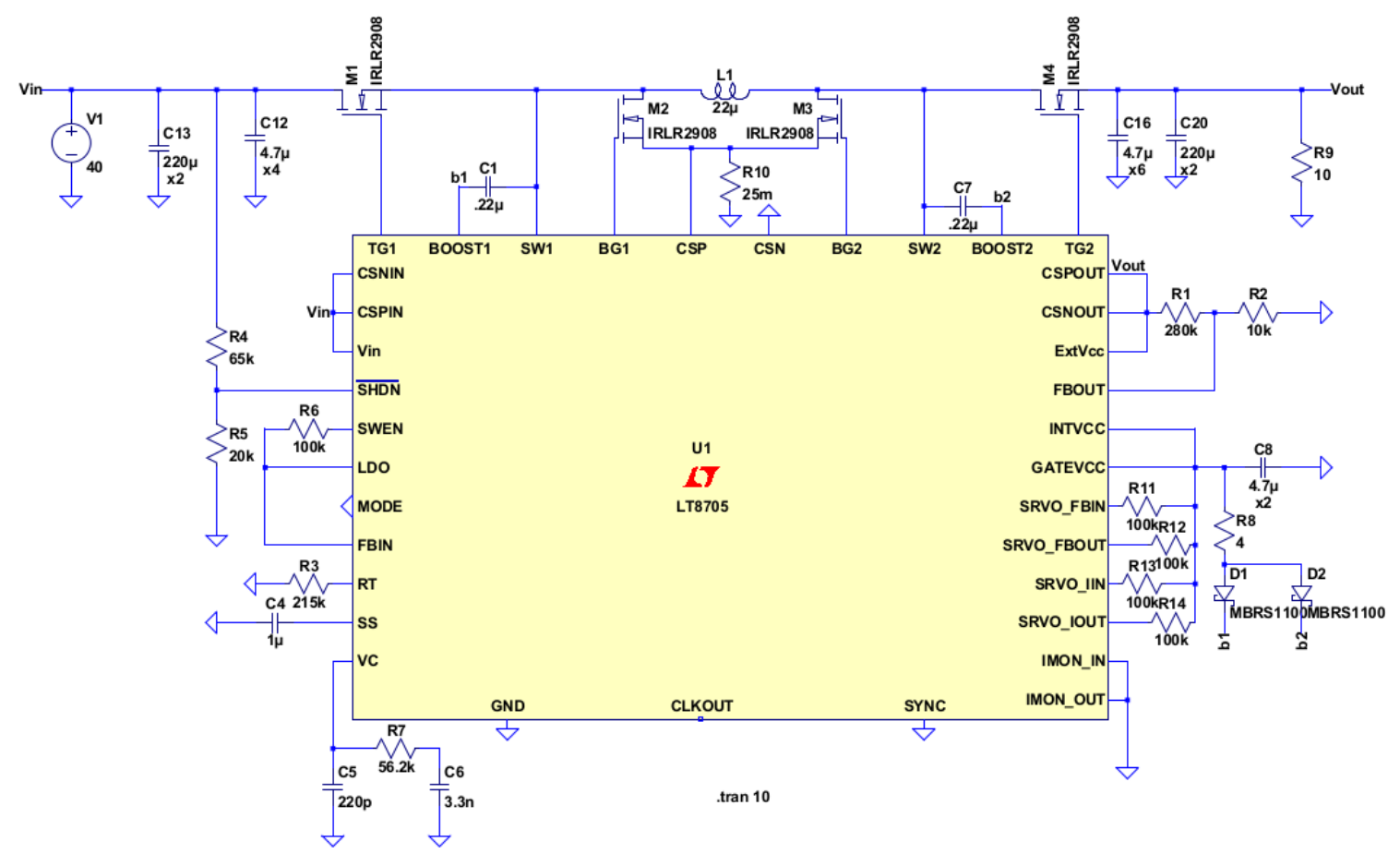

Figure 4.3: Iteration 2 Circuit Diagram

\subsection{Iteration 3}

Comparison to a previous implementation of this converter [22] shows that the rightmost transistor M4 was rotated improperly. The body of the transistor was connected to the output voltage instead of the right side of the inductor. This correction allowed the output voltage to meet specification at all input levels. Figure 4.4 shows the new circuit, and 
Figure 4.5 shows how the average output voltage with any input manages to reach $36 \mathrm{~V}$. To conduct this simulation in a reasonable amount of time, the soft start capacitor was set to $10 n F$.

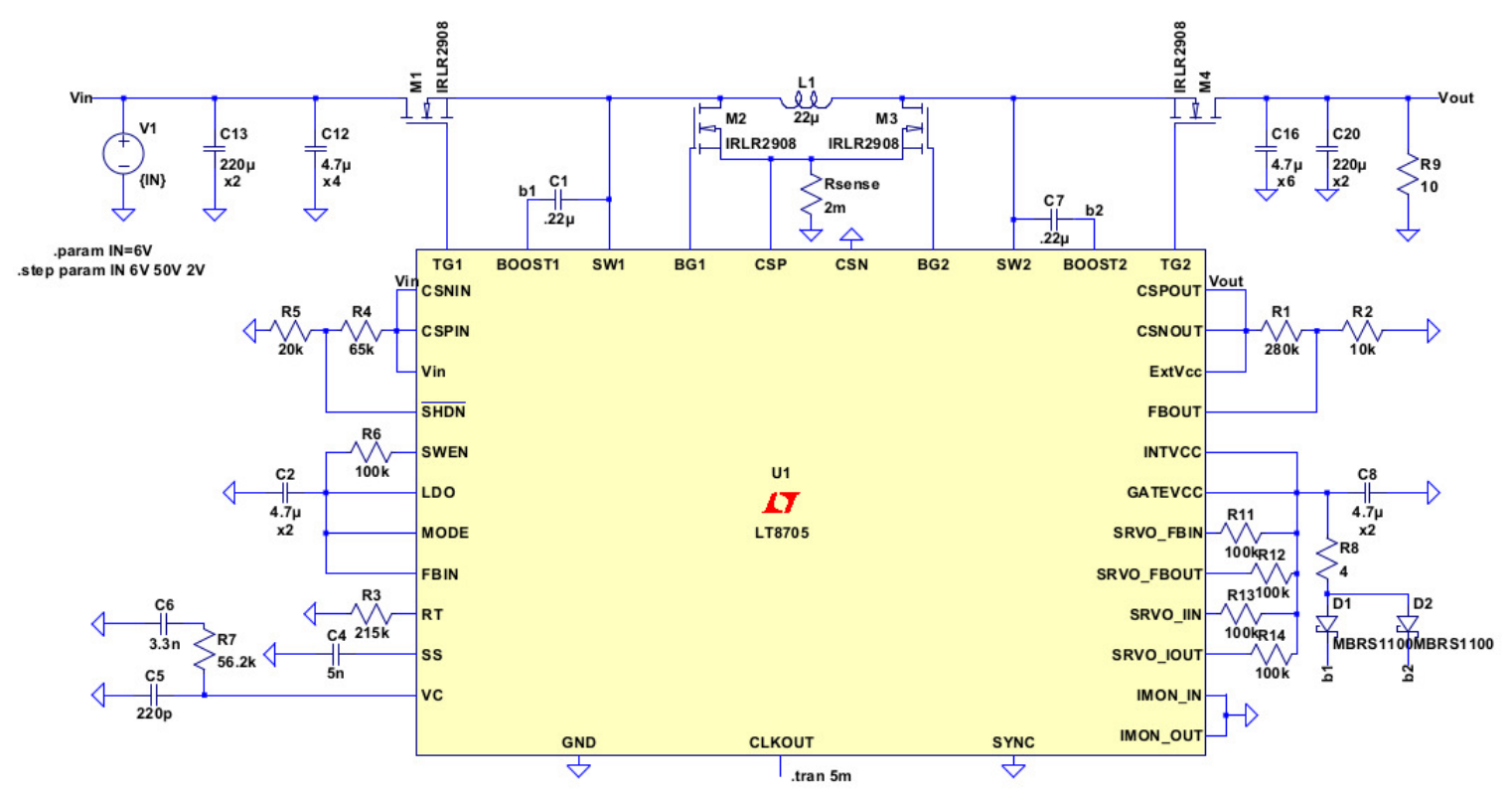

Figure 4.4: Simulation 3 Circuit Diagram

Another change between this iteration and the last is the mode of operation. With the MODE pin set high, the converter operates in discontinuous operation mode. This counterproductive choice survived an iteration set because of the author's ignorance of the subject. The mode change had no noticeable effect in simulation. Fortunately, the end product leaves the mode pin as a configuration option, and physical implementations avoid discontinuous conduction mode.

\subsection{Iteration 4}

With the basic functionality accomplished, a final round of datasheet-strict component calculations produces the end values for the sense resistance and the inductor size.

Having taken formal power electronics courses, the project moved toward efficiency maximization and the logistics of the functional design. For the MOSFETs, the balance 


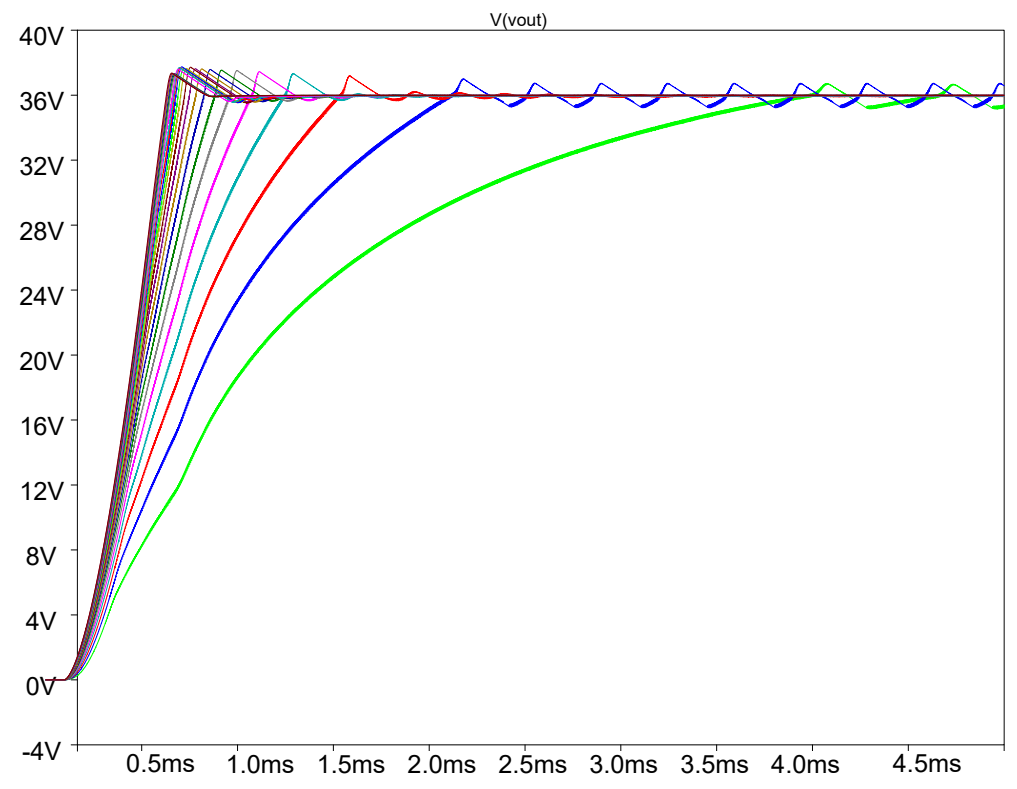

Figure 4.5: Iteration 3 output voltage, from $6 \mathrm{~V}$ to $50 \mathrm{~V}$ in steps of $2 \mathrm{~V}$

of on resistance and gate capacitance affects efficiency. Additionally, the inductor must handle the startup and steady state currents without saturating.

The FDMS86255 was selected for the MOSFETs because of their high power dissipation and low $R_{D S, o n}$. Also critical to this choice was the availability of the online availability of the Spice model. Figure 5.3 is a zoomed in version of this simulation's output at $50 \mathrm{~V}$ at the largest peak, measured as power in M2. This peak occurred during start up. The steady state power dissipation is much smaller. M2 was deemed a risk factor because it would experience simultaneous high voltage and current when in buck mode. The single pulse avalanche energy $E_{A S}$ for the FDMS86255, listed as $541 \mu \mathrm{J}$, is well above the pulse energies generated by the hard switching converter. [23] 


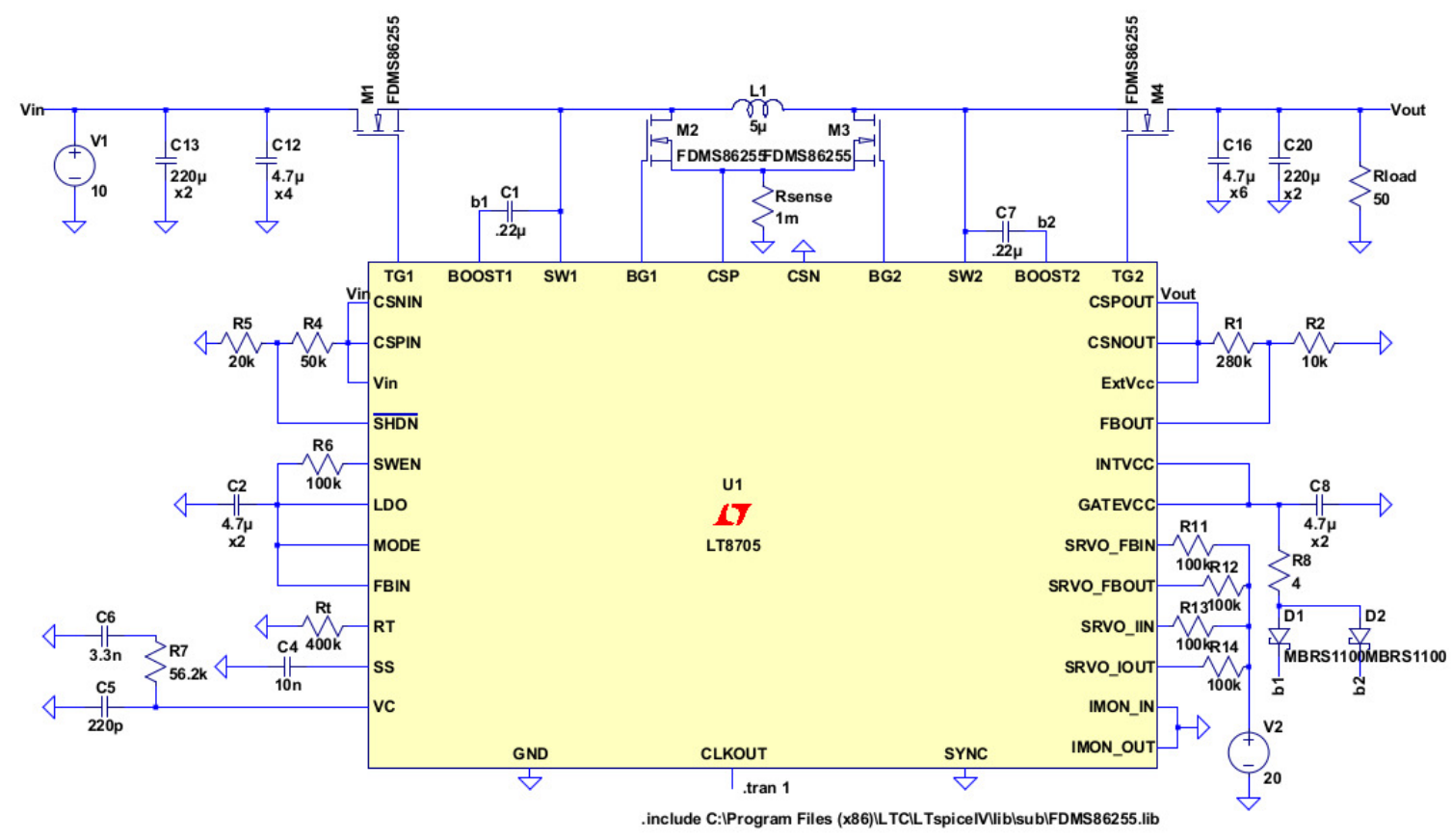

Figure 4.6: Iteration 4 Circuit Diagram 


\section{Chapter 5: MOSFET Testing}

Previous projects have had issues with MOSFET failure. Hard switching converter topologies experience sharp spikes in drain-source power dissipation when they turn on. While the total energy in each spike may not reach the single-pulse avalanche energy limit, the high switching frequency of the converter could drive the average power dissipation above the MOSFET's rating. If not, the same issue could occur with an inadequate heat conduction rate from the junction to the case.

These concerns motivate a precautionary characterization and stress test of the MOSFETs before PCB fabrication. These tests measure any device degradation, if any, that would occur at the operational limits of the DC-DC converter.

Common power MOSFET metrics are the on resistance $R_{D S, \text { on }}$, the threshold gatesource voltage $V_{G S}$, the breakdown drain-source voltage $B V_{D S}$, and the IV characteristic curve. However, present resources limit testing to lower current metrics. This report instead evaluates sub-threshold current curves $I V_{s u b}$ and zero gate voltage drain current $I_{D S S}$. A summary of the test plan is shown in Table 5.1.

Table 5.1: Metric evaluation plan

\begin{tabular}{|c|l|l|}
\hline & Before Stress Test & After Stress Test \\
\hline$B V_{D S}$ & & \\
\hline$I V_{\text {sub }}$ & & \\
\hline$I_{D S S}$ & & \\
\hline
\end{tabular}

First, the device is characterized using the three metrics. The device, having been warmed by the tests, is recharacterized. This measures the variance between a cold MOSFET and a warm MOSFET. Then the unit is stressed by subjecting it to a common use case scenario for five minutes. Lastly, the device is characterized a third time. The data from this characterization provides the variance between the warm MOSFET and the cold MOSFET. 


\subsection{Initial Characterization}

The test instruments are controlled by a LabVIEW Sweep-and-Go [24] program for each characterization test. The test setup is shown in Figure 5.1.

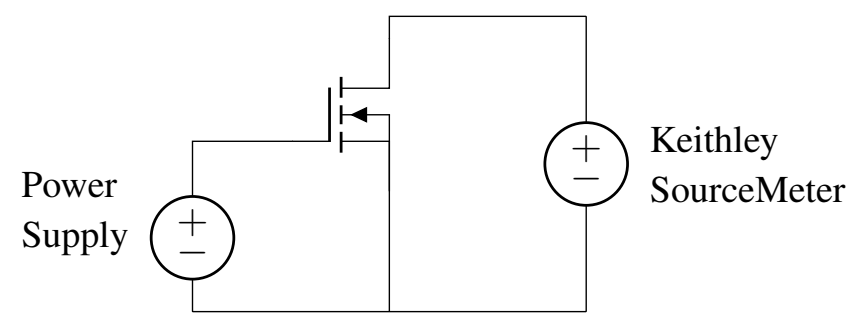

Figure 5.1: MOSFET characterization test setup

For $B V_{D S}$ and $I_{D S S}$, the Agilent power supply is set to $0 \mathrm{~V}$. The Keithley Sourcemeter current compliance is set to $100 \mu \mathrm{A}$. It ramps $V_{D S}$ from 0 to $100 \mathrm{~V}$ in steps of $1 \mathrm{~V}$, while monitoring $I_{D S} . B V_{D S}$ is the point at which the Sourcemeter's compliance rating is reached. On the graph, it appears as a plateau in the drain-source current.

The sub-threshold current curves are drawn by setting $V_{D S}$ to $5 V$. $V_{G S}$ ramps from $0.5 \mathrm{~V}$ to $1.75 \mathrm{~V}$ in steps of $0.05 \mathrm{~V}$.

Characterization is conducted twice, accounting for measurement variance and stressed/nonstressed variance.

\subsection{Stress Testing}

The most dramatic use case for the MOSFET is at a converter input voltage of $50 \mathrm{~V}$. This produces the highest voltage across the MOSFET and the largest power spikes. The components in Figure 5.2 are calculated to reproduce these conditions, including the pulse energy derived from simulation. The Keithley is used as a power supply to charge the capacitor on each cycle. The pulse generator produces $10 \mathrm{~ns}$ pulses at $100 \mathrm{kHz}$, which approximates the length of each power spike found in simulation. The pulses must be at least $5 V_{p-p}$. 


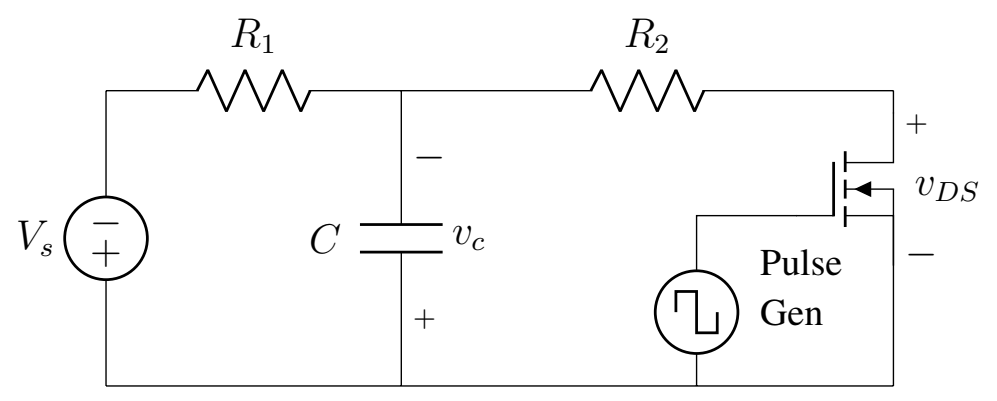

Figure 5.2: Stress testing circuit

The following equations inform the component choices. Constants come from simulation data, shown in Figures 5.3 and 5.4.

$$
\begin{aligned}
\frac{1}{2} C V_{s}^{2} & =97.7 \mu J \\
D & =(99.2 n s) f_{s w} \\
(1-D) T & =5 R_{1} C \\
\frac{V_{s}}{R_{2}} & =5 \mathrm{~A}
\end{aligned}
$$

Using $V_{s}=50 \mathrm{~V}$ and $f=110 \mathrm{kHz}$ (this test occurred before deciding the final running frequency of $200 \mathrm{kHz}$ ), these equations result in $R_{1}=23 \Omega, R_{2}=5 \Omega$, and $C=78.16 n C$.

The MOSFET is tested under these conditions for five minutes, enough time to damage the MOSFET if there exists a minor weakness from the stress. When the test is over, a final characterization is conducted.

If the variance in the performance metrics before and after the stress test is at the same order of magnitude as the stressed/unstressed initial characterization, this project concludes that the MOSFETs can handle the conditions of the DC-DC converter without sustaining damage. 


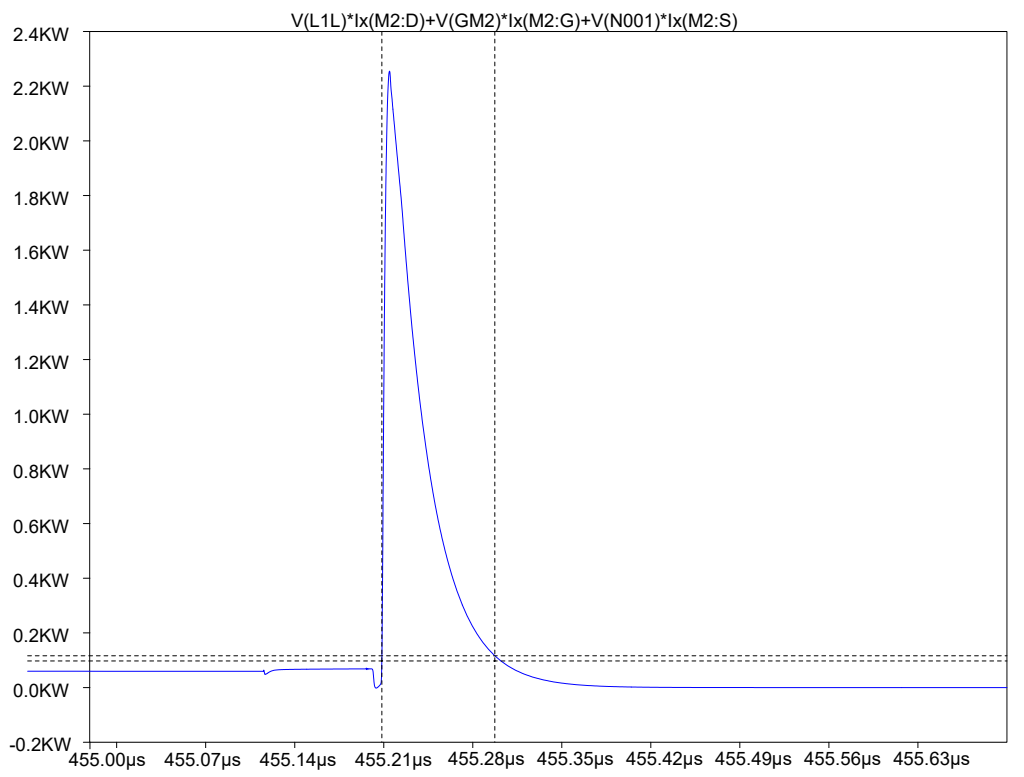

Figure 5.3: Dimensions of largest power spike for $50 \mathrm{~V}$ input

$\mathcal{L}$ Waveform: $\mathrm{V}(\mathrm{L} 1 \mathrm{~L})^{\star} \mid x(\mathrm{M} 2: \mathrm{D})+\ldots \quad \times$

\begin{tabular}{rl|} 
Interval Start: & $454.9 \mu \mathrm{s}$ \\
Interval End: & $456.1 \mu \mathrm{s}$ \\
Average: & $81.423 \mathrm{~W}$ \\
Integral: & $97.708 \mu \mathrm{J}$
\end{tabular}

Figure 5.4: LTspice waveform characteristics 


\subsection{Results}

Instead of the FDMS86255 MOSFETs, specified in simulation, testing used the similarly characterized OnSemi transistor, the NDPL180N10B. The OnSemi product had a package more favorable to testing and heat sinking (the FDMS86255 transistors were small, surface mount, and had an epoxy package).

Figure 5.5 shows the drain current responses to drain-source voltage with the gate tied to ground. As the plot shows, warming the MOSFET had a minor effect on the drain-source IV characteristic. The stress testing had less of an effect on the IV curve than the warming.

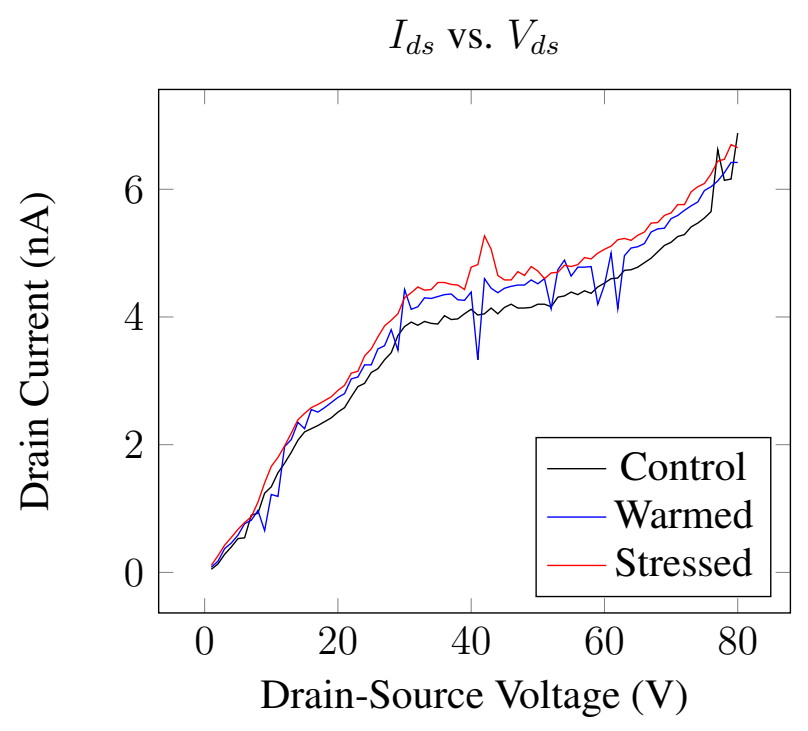

Figure 5.5: Drain-source subthreshold IV curves

Figure 5.6 shows the subthreshold drain current characteristic curves as a function of gate-source voltage, on a semi-log plot. To compare the curves, I compared the slope of their turn on speeds using the tangent between $V_{g s}=2 \mathrm{~V}$ and $V_{g s}=2.75 \mathrm{~V}$.

Table 5.2 details the results of this comparison. The variance between stressed and warmed is so small as to be negligible. 


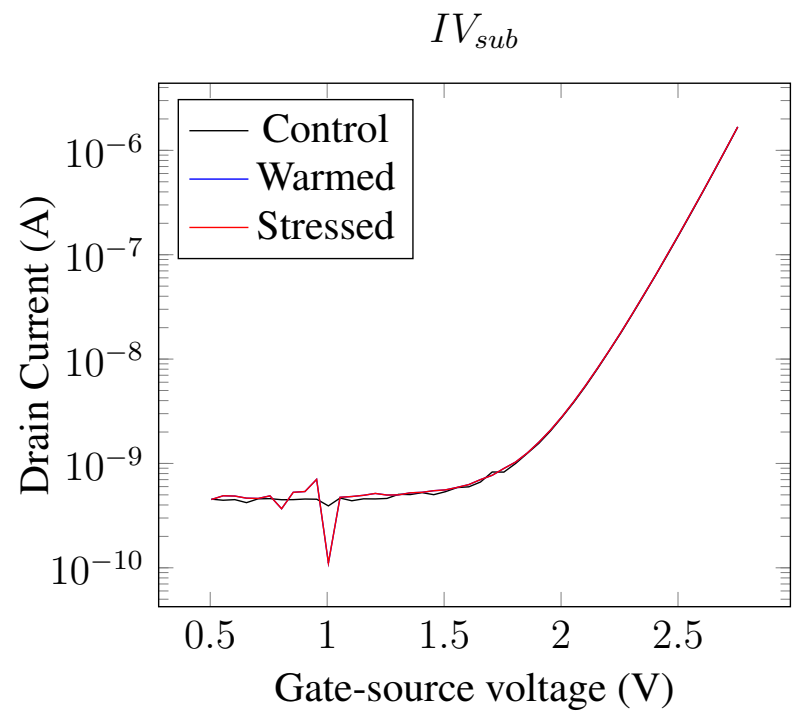

Figure 5.6: Sub-threshold current characteristics

Table 5.2: Subthreshold current slopes

\begin{tabular}{lllc}
\hline & $\frac{d e c}{V}$ & $\frac{m V}{d e c}$ & Variance \\
\hline Control & 3.7028 & 270.0069 & $0 \%$ \\
Warmed & 3.697115 & 270.4812 & $0.176 \%$ \\
Stressed & 3.69711 & 270.48121 & $3.697 \times 10^{-6 \%}$ \\
\hline
\end{tabular}




\subsection{Conclusion}

The variance in the turn-on performance between an unstressed MOSFET and a stressed MOSFET is less the variance between a cold MOSFET and a warm MOSFET. These results suggest that the MOSFETs will not suffer damage under worst-case-scenario operational conditions. This report acknowledges, however, that the low-current parameters used to characterize the devices are divorced from the high current normal operation of the device. 


\section{Chapter 6: PCB Design}

This chapter describes the design process for the physical printed circuit board. Immediate concerns are for the sizing of heat sinks for the T0-220 package MOSFETs, trace length minimization of gate control signals, and isolation of power ground planes and signal ground planes.

The DC-DC converter must physically fit within the confines of the Precor Elliptical machine, in the same chamber where the user motion converts to electricity. This has a fortunate benefit of ensuring a high ambient air velocity, which should help keep the MOSFETs cool.

\subsection{Revisions 1 and 2}

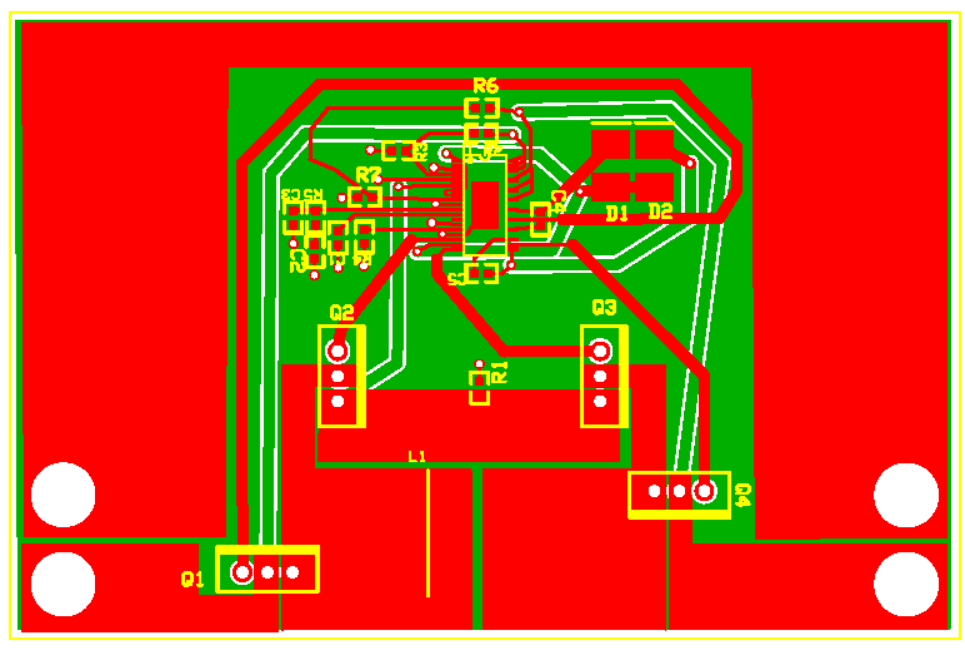

Figure 6.1: Rev 1 board

Figure 6.1 shows the first draft of the board, designed in ExpressPCB software, known for its quick prototyping turnaround [25]. The first draft uses two copper layers. This draft was used to gain familiarity with the program and the principles of PCB design.

Subsequent revisions use four copper layers. This allows for dedicated power ground planes and signal ground planes, and for more isolated signals. Figure 6.2 omits the two 


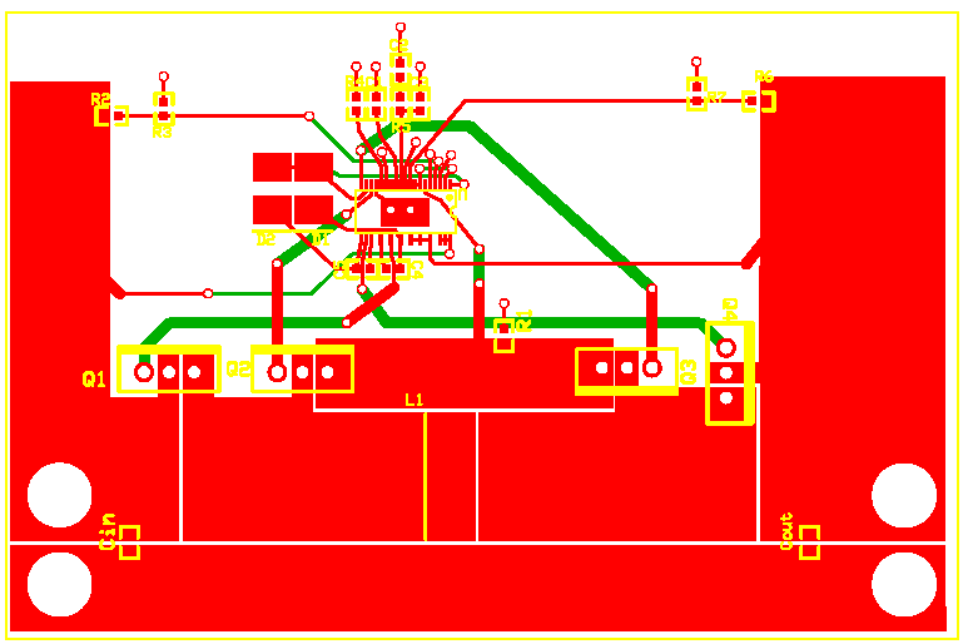

Figure 6.2: Rev 2 board

copper planes that provide EMI shielding and separate power ground and signal ground at all but the point under the LT8705 chip.

Issues addressed between the second draft, shown in Figure 6.2, include the location of power ground. In draft 1 , the power ground plane, connected to both the input and output grounds, wraps around the top and sides of the board, which was deemed too long a path. By switching the input and output vertically with power ground, the ground path can stretch cleanly along the bottom for a shorter, quieter path.

The MOSFET gate trace lengths are also shortened, to minimize cross talk between signals, which can be as short as $10 \mathrm{~ns}$ and are thus very sensitive to those effects. The gate signals for the outside MOSFETs cross at ninety degree angles, but these two traces are on opposite sides of the board, separated by two layers of copper.

A third revision, never fabricated, resizes the ground planes, adjust trace widths, and accounts for large heat sink footprints. More input and output capacitors are added, sized larger for better noise filtering.

Unfortunately, this revision was finished only shortly before the end of the school year, and thus never got a thorough test, other than a quick inspection to see that it did not work. 


\subsubsection{Switching Software}

This project quickly moved away from ExpressPCB to more sophisticated, free alternatives. Eagle is a popular CAD program with a trial version that matches the capabilities of ExpressPCB and includes useful tools like an autorouter, a strong design rule checker, and a command line interface for precise part placement [25]. However, the free version places limits on board size and can only handle two copper layers. After some experimentation, the project settled on $\mathrm{KiCad}$, a free and open source CAD program that allows for up to thirty-two copper layers and places no limits on board size [26].

\subsection{Revision 3}

Lessons from the first physical iteration of the board include:

1. Break out critical nodes in a header pin for real time evaluation.

2. Use pin headers for configuration. For example, the MODE pin can be broken out and connected to GND or the LDO with a header jumper.

3. Do not use unnecessarily small packages for surface mount resistors and capacitors. The power path requires large components anyway, which makes the board large and provides room to spare for resistors and capacitors.

4. Kicad offers separate footprints for hand soldering, with longer pads that a soldering iron can reach.

In addition, quick consultation with Joshua Quintero, a Field Applications Engineer at Linear Technology provided an enlightening set of pointers:

1. The input and output should have a combination of electrolytic and ceramic capacitors for effective noise filtering and to reduce ESR for minimum power loss.

2. $R_{T}$, the frequency setting resistor, should be placed close to the chip. 
3. The sense resistor benefits from the reduced inductance of wider, shorter packages.

4. To prevent ringing, add a small gate resistance to each MOSFET.

5. Power56 package transistors like Fairchild's FDMS series can indeed be used for switching converters like this. The large drain pad helps dissipate heat very efficiently. Large areas of copper on the board can be used as a heat sink.

These thoughts were combined into the new design, seen in Figure 6.4. Immediately after fabricating, however, a couple mistakes became obvious.

Two signal traces pass through the power ground on the top layer, interrupting the continuity. This forces power circuit currents to pass through a small via that links power ground on top, bottom, and center layers. This via presents a small resistance placed in series with the loop created by the input voltage, the left MOSFETs, and the sense resistor. Because the sense resistor is so small $(1 \mathrm{~m} \Omega)$, this makes a voltage divider, reducing the voltage seen across the sense resistor. This issue is illustrated in Figure 6.3.

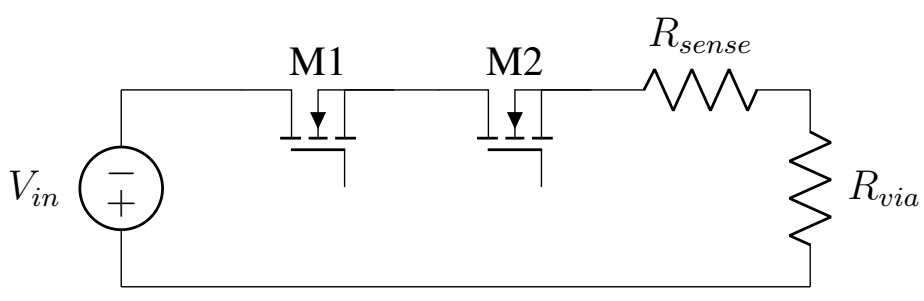

Figure 6.3: Effects of via in power path circuits

Signal ground and power ground meet in several places. Ideally, they should only meet in one location very near to the controller. This design has a couple crossings on the bottom and top layers that ruin this effect. A blue rectangle in Figure 6.4 shows a crossing on the top layer.

Later iterations remove these issues by reorganizing signal traces to keep a smooth, uninterrupted power ground and connecting it to signal ground at only one point. 


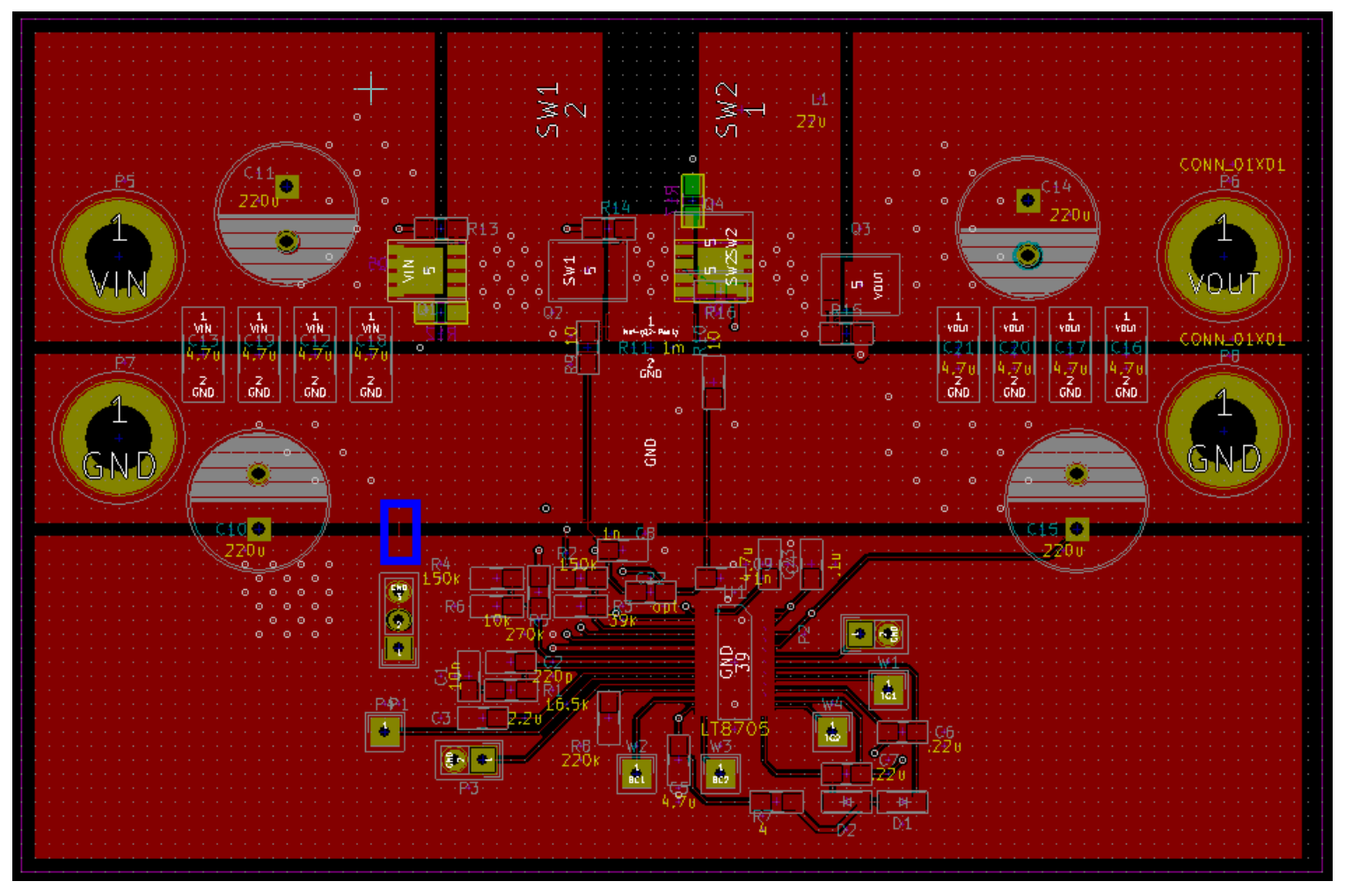

Figure 6.4: Rev 3 board 


\section{Chapter 7: Converter Testing}

With the DC-DC converter designed and assembled, this chapter discusses the characterization of the device and documents the attempt to integrate it into the EHFEM system.

To isolate faults that might occur during integration, this project tests the converter first in isolation, and then for compatibility with the other components of the EHFEM system.

The order of converter tests is as follows:

1. Converter functional tests.

2. Elliptical to converter integration tests.

3. Converter to inverter integration tests.

4. Elliptical to converter to inverter full integration tests.

\subsection{Converter Functional Tests}

These tests study the converter efficiency and load and line regulation. Figure 7.1 shows a basic diagram of the test setup. A BK Precision DC source powers the converter, and it drives an electronic load set to constant current. Data are collected for load currents between 1 and $4 \mathrm{~A}$, and over input voltages of 10 to $60 \mathrm{~V}$.

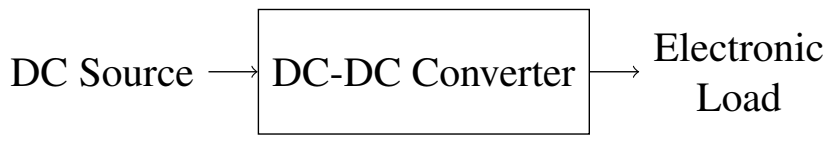

Figure 7.1: Test setup for converter operation

The BK Precision DC source has a current limit of 9.1 A, which prohibits lower input voltages, especially at higher load current. The relationship in Equation 7.1 must hold true for each data point, so the BK Precision DC source cannot generate some data points.

$$
9.1 A>\frac{V_{\text {out }}}{V_{\text {in }}} I_{\text {load }}
$$


This project also tests the converter in two modes of operation: burst mode, which hysteretically disables switching to maximize efficiency in light load conditions, and forced continuous mode, which allows inductor current to reverse direction without forcing switches off. Burst mode results are shown in Table 7.1. Forced continuous mode results are shown in Table 7.2.

\subsubsection{Regulation}

The load and line regulation figures are calculated from these data. Line regulation comes from output voltages produced from input voltages at $10 \mathrm{~V}$ and $60 \mathrm{~V}$ at $1 \mathrm{~A}$ load current. Load regulation is calculated with $V_{i n}=35 \mathrm{~V}$ at load currents of $1 \mathrm{~A}$ and 4 A. Table 7.3 shows the results.

These results suggest that the converter can adequately maintain a $36 \mathrm{~V}$ output for the microinverter to use. Any regulation still fits within the efficiency window for the microinverter.

\subsubsection{Efficiency}

The converter maintains greater than $84 \%$ efficiency for all input voltages at all tested load currents in both burst mode and continuous conduction mode. Across all input voltages, the converter has an average efficiency of $90.9 \%$ in burst mode and $93.2 \%$ in CCM. This meets the efficiency requirement specified in Table 2.1 .

Figures 7.2 and 7.3 illustrate the converter efficiency curves as a function of input voltage. Each curve represents a different load current. Each graph represents a different mode of operation. For both modes, the efficiency hits a local peak at $25 V_{i n}$. The CCM graph shows a distinct trough at the buck-boost region of operation. 
Table 7.1: Burst mode test results

\begin{tabular}{|c|c|c|c|c|c|c|}
\hline $\begin{array}{r}\text { Ideal } \\
I_{\text {load }}\end{array}$ & $\begin{array}{c}\text { Measured } \\
I_{\text {load }}\end{array}$ & $\begin{array}{c}\text { Ideal } \\
V_{i n}\end{array}$ & $\begin{array}{c}\text { Measured } \\
V_{i n}\end{array}$ & $V_{\text {out }}$ & $I_{\text {in }}$ & $P_{\text {out }} / P_{\text {in }}$ \\
\hline 1 & 1.00 & 10 & 10.00 & 35.85 & 3.96 & 0.904 \\
\hline 1 & 1.00 & 15 & 15.00 & 35.91 & 2.56 & 0.932 \\
\hline 1 & 1.00 & 20 & 20.00 & 35.86 & 1.95 & 0.918 \\
\hline 1 & 1.00 & 25 & 25.00 & 35.89 & 1.53 & 0.937 \\
\hline 1 & 1.00 & 30 & 30.00 & 35.96 & 1.32 & 0.907 \\
\hline 1 & 1.00 & 35 & 35.00 & 36.05 & 1.13 & 0.912 \\
\hline 1 & 0.99 & 40 & 40.00 & 36.01 & 0.98 & 0.907 \\
\hline 1 & 1.00 & 45 & 45.00 & 36.01 & 0.90 & 0.891 \\
\hline 1 & 0.99 & 50 & 50.00 & 36.03 & 0.82 & 0.877 \\
\hline 1 & 1.00 & 55 & 55.00 & 36.03 & 0.73 & 0.899 \\
\hline 1 & 1.00 & 60 & 60.00 & 36.05 & 0.68 & 0.887 \\
\hline 2 & 2.00 & 10 & 10.00 & 35.78 & 8.39 & 0.852 \\
\hline 2 & 2.00 & 15 & 15.00 & 35.83 & 5.18 & 0.921 \\
\hline 2 & 2.00 & 20 & 20.00 & 35.86 & 3.83 & 0.936 \\
\hline 2 & 2.00 & 25 & 25.00 & 35.91 & 3.04 & 0.945 \\
\hline 2 & 2.00 & 30 & 30.00 & 36.04 & 2.60 & 0.924 \\
\hline 2 & 2.00 & 35 & 35.00 & 36.08 & 2.24 & 0.922 \\
\hline 2 & 2.00 & 40 & 40.00 & 36.02 & 1.99 & 0.905 \\
\hline 2 & 2.00 & 45 & 45.00 & 36.01 & 1.77 & 0.905 \\
\hline 2 & 2.00 & 50 & 50.00 & 36.02 & 1.59 & 0.905 \\
\hline 2 & 2.00 & 55 & 55.00 & 36.03 & 1.46 & 0.896 \\
\hline 2 & 2.00 & 60 & 60.00 & 36.03 & 1.34 & 0.896 \\
\hline 3 & 3.00 & 15 & 15.00 & 35.76 & 7.97 & 0.897 \\
\hline 3 & 3.00 & 20 & 20.00 & 35.80 & 5.75 & 0.934 \\
\hline 3 & 3.00 & 25 & 25.00 & 35.84 & 4.59 & 0.937 \\
\hline 3 & 3.00 & 30 & 30.00 & 35.98 & 3.92 & 0.917 \\
\hline 3 & 3.00 & 35 & 35.00 & 36.03 & 3.36 & 0.918 \\
\hline 3 & 3.00 & 40 & 40.00 & 36.00 & 2.96 & 0.910 \\
\hline 3 & 3.00 & 45 & 45.00 & 36.03 & 2.67 & 0.900 \\
\hline 3 & 3.00 & 50 & 50.00 & 36.01 & 2.40 & 0.903 \\
\hline 3 & 3.00 & 55 & 55.00 & 36.02 & 2.18 & 0.903 \\
\hline 3 & 3.00 & 60 & 60.00 & 36.04 & 2.01 & 0.897 \\
\hline 4 & 4.00 & 25 & 20.00 & 35.72 & 7.81 & 0.914 \\
\hline 4 & 4.00 & 30 & 25.00 & 35.78 & 6.17 & 0.928 \\
\hline 4 & 4.00 & 35 & 35.00 & 36.01 & 4.48 & 0.918 \\
\hline 4 & 4.00 & 40 & 40.00 & 36.94 & 3.95 & 0.934 \\
\hline 4 & 4.00 & 45 & 45.00 & 35.96 & 3.55 & 0.901 \\
\hline 4 & 4.00 & 50 & 50.00 & 36.01 & 3.20 & 0.899 \\
\hline 4 & 4.00 & 55 & 55.00 & 35.99 & 2.91 & 0.899 \\
\hline 4 & 4.00 & 60 & 60.00 & 35.99 & 2.67 & 0.899 \\
\hline
\end{tabular}


Table 7.2: CCM test results

\begin{tabular}{|c|c|c|c|c|c|c|}
\hline $\begin{array}{l}\text { Ideal } \\
I_{\text {load }}\end{array}$ & $\begin{array}{c}\text { Measured } \\
I_{\text {load }} \\
\end{array}$ & $\begin{array}{c}\text { Ideal } \\
V_{i n}\end{array}$ & $\begin{array}{c}\text { Measured } \\
V_{i n}\end{array}$ & $V_{\text {out }}$ & $I_{\text {in }}$ & $P_{\text {out }} / P_{\text {in }}$ \\
\hline 1 & 1.00 & 10 & 10.00 & 35.85 & 3.96 & 0.904 \\
\hline 1 & 1.00 & 15 & 15.00 & 35.91 & 2.56 & 0.933 \\
\hline 1 & 1.00 & 20 & 20.00 & 35.96 & 1.91 & 0.942 \\
\hline 1 & 1.00 & 25 & 25.00 & 36.01 & 1.52 & 0.946 \\
\hline 1 & 1.00 & 30 & 30.00 & 36.06 & 1.27 & 0.946 \\
\hline 1 & 1.00 & 35 & 35.00 & 36.34 & 1.15 & 0.899 \\
\hline 1 & 1.00 & 40 & 40.00 & 36.45 & 1.01 & 0.899 \\
\hline 1 & 1.00 & 45 & 45.00 & 36.24 & 0.86 & 0.934 \\
\hline 1 & 1.00 & 50 & 50.00 & 36.29 & 0.78 & 0.928 \\
\hline 1 & 1.00 & 55 & 55.00 & 36.35 & 0.72 & 0.922 \\
\hline 1 & 1.00 & 60 & 60.00 & 36.41 & 0.66 & 0.918 \\
\hline 2 & 2.00 & 10 & 10.00 & 35.78 & 8.44 & 0.847 \\
\hline 2 & 2.00 & 15 & 15.00 & 35.83 & 5.19 & 0.921 \\
\hline 2 & 2.00 & 20 & 20.00 & 35.88 & 3.80 & 0.943 \\
\hline 2 & 2.00 & 25 & 25.00 & 35.93 & 3.03 & 0.949 \\
\hline 2 & 2.00 & 30 & 30.00 & 36.14 & 2.62 & 0.920 \\
\hline 2 & 2.00 & 35 & 35.00 & 36.24 & 2.24 & 0.924 \\
\hline 2 & 2.00 & 40 & 40.00 & 36.36 & 1.96 & 0.928 \\
\hline 2 & 2.00 & 45 & 45.00 & 36.16 & 1.68 & 0.953 \\
\hline 2 & 2.00 & 50 & 50.00 & 36.21 & 1.52 & 0.950 \\
\hline 2 & 2.00 & 55 & 55.00 & 36.27 & 1.39 & 0.945 \\
\hline 2 & 2.00 & 60 & 60.00 & 36.33 & 1.29 & 0.941 \\
\hline 3 & 3.00 & 15 & 15.00 & 35.75 & 7.97 & 0.896 \\
\hline 3 & 3.00 & 20 & 20.00 & 35.80 & 5.75 & 0.933 \\
\hline 3 & 3.00 & 25 & 25.00 & 35.85 & 4.55 & 0.945 \\
\hline 3 & 3.00 & 30 & 30.00 & 36.03 & 3.93 & 0.916 \\
\hline 3 & 3.00 & 35 & 35.00 & 36.17 & 3.34 & 0.928 \\
\hline 3 & 3.00 & 40 & 40.00 & 36.27 & 2.91 & 0.934 \\
\hline 3 & 3.00 & 45 & 45.00 & 36.08 & 2.51 & 0.957 \\
\hline 3 & 3.00 & 50 & 50.00 & 36.13 & 2.27 & 0.955 \\
\hline 3 & 3.00 & 55 & 55.00 & 36.18 & 2.07 & 0.952 \\
\hline 3 & 3.00 & 60 & 60.00 & 36.24 & 1.91 & 0.949 \\
\hline 4 & 4.00 & 20 & 20.00 & 35.73 & 7.79 & 0.918 \\
\hline 4 & 4.00 & 25 & 25.00 & 35.78 & 6.11 & 0.937 \\
\hline 4 & 4.00 & 30 & 30.00 & 35.91 & 5.22 & 0.917 \\
\hline 4 & 4.00 & 35 & 35.00 & 36.09 & 4.46 & 0.925 \\
\hline 4 & 4.00 & 40 & 40.00 & 36.18 & 3.87 & 0.934 \\
\hline 4 & 4.00 & 45 & 45.00 & 36.00 & 3.35 & 0.955 \\
\hline 4 & 4.00 & 50 & 50.00 & 36.05 & 3.02 & 0.955 \\
\hline 4 & 4.00 & 55 & 55.00 & 36.10 & 2.75 & 0.953 \\
\hline 4 & 4.00 & 60 & 60.00 & 36.16 & 2.54 & 0.948 \\
\hline
\end{tabular}


Table 7.3: Converter load and line regulation

\begin{tabular}{rcc}
\hline & Line Regulation & Load Regulation \\
\hline Burst Mode & $0.56 \%$ & $0.14 \%$ \\
Forced Continuous Mode & $1.56 \%$ & $0.694 \%$ \\
\hline
\end{tabular}

Burst Mode Efficiency

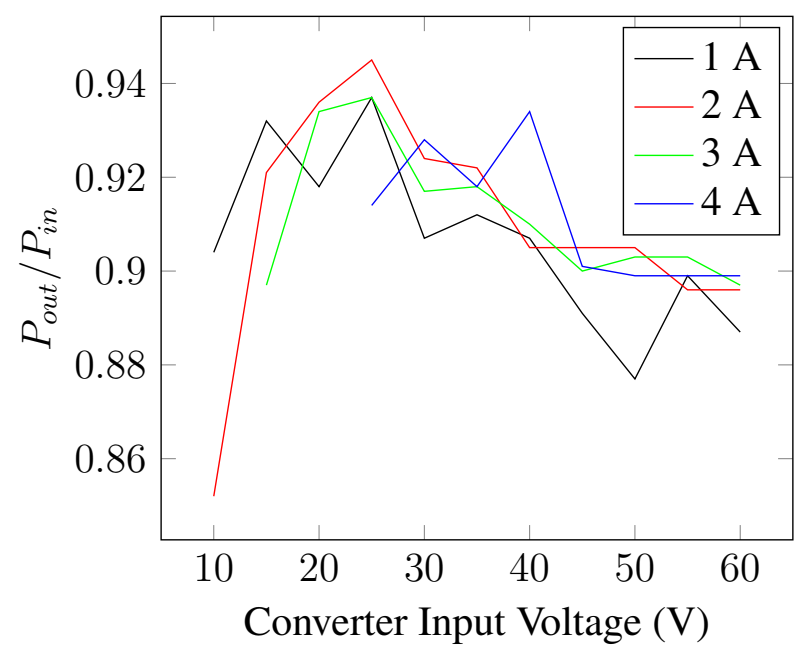

Figure 7.2: Burst mode efficiency for different load currents

CCM Efficiency

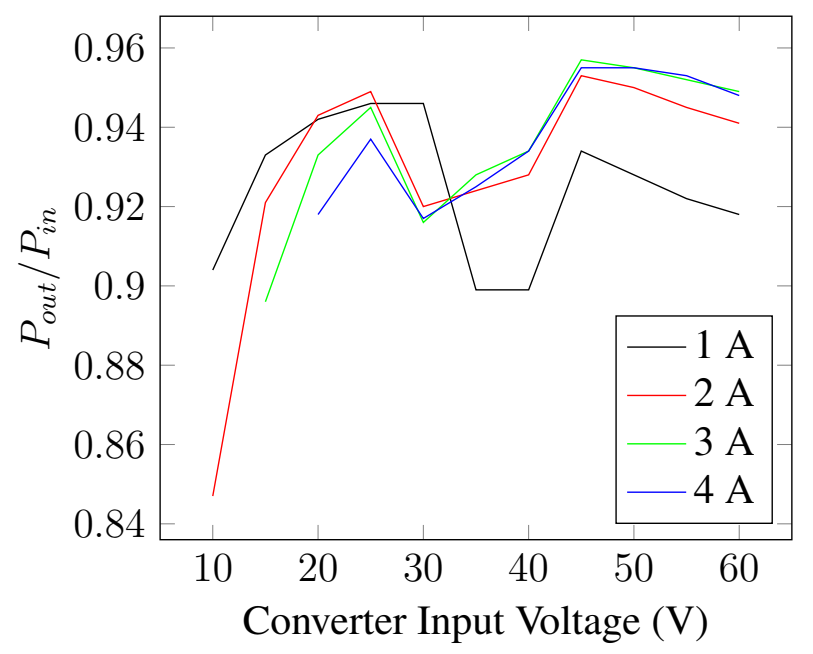

Figure 7.3: CCM efficiency for different load currents

\subsubsection{Input Resistance}

Figures 7.4 and 7.5 show the input current-voltage curves for the converter. These plots include a dashed line representing $10 \Omega$. The converter specification asked for an input 
resistance of $10 \Omega$ for all loads. These plots demonstrate that the converter failed to meet that specification. Converter input resistance varies widely from as high as $88.235 \Omega$ (at $I_{L}=0.68 \mathrm{~A}$ and $\left.V_{\text {in }}=60 \mathrm{~V}\right)$ to as low as $1.18 \Omega\left(\right.$ at $I_{L}=8.44 \mathrm{~A}$ and $\left.V_{\text {in }}=10 \mathrm{~V}\right)$. This means that the EHFEM project cannot integrate the DC-DC converter without input protection that possibly relies on the existing large resistors.

Input IV Curves for Burst Mode

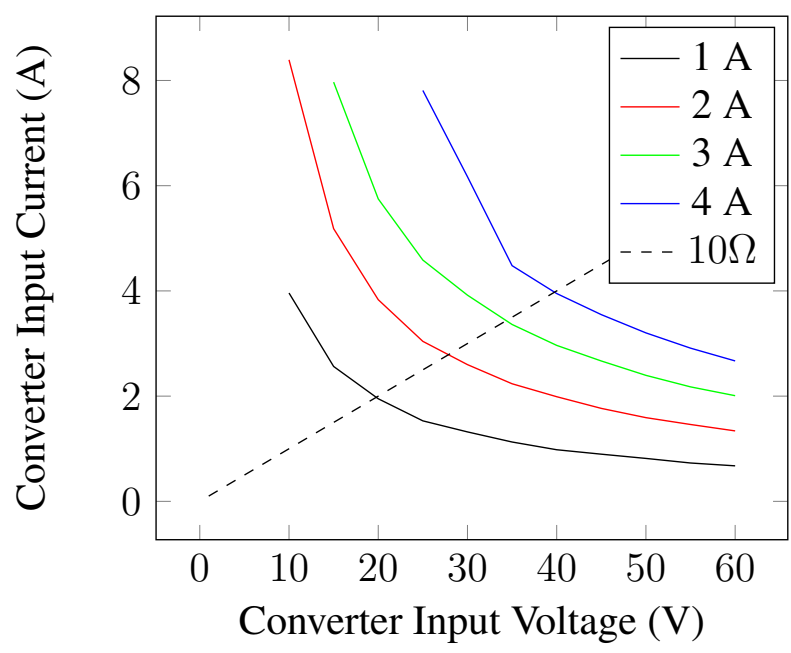

Figure 7.4: Converter IV curves in burst mode

Input IV Curves for Forced Continuous Mode

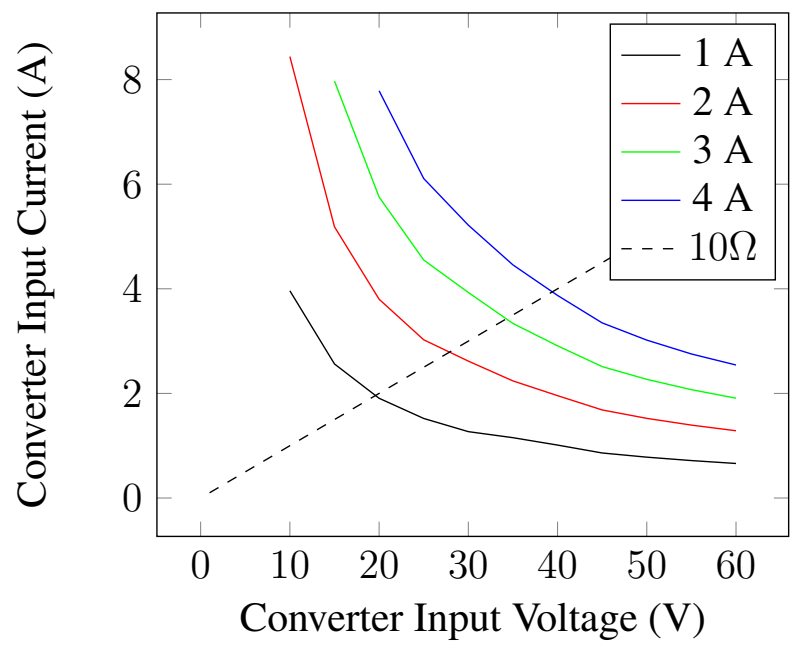

Figure 7.5: Converter IV curves in forced continous mode

The converter meets efficiency and regulation requirements, but not the input resistance 
specification. The next section discusses the relationship between the elliptical machine and the DC-DC converter.

\subsection{Elliptical Machine to Converter Integration Tests}

This section describes the first step in the integration process. Before placing the DCDC converter between the elliptical machine and the microinverter, two intermediate tests determine converter-elliptical compatibility and converter-microinverter compatibility.

Figure 7.6 shows the high level test setup. The input protection is connected in parallel with the $20 \Omega$ load resistors in the back of the elliptical machine. If the input voltage exceeds $60 \mathrm{~V}$, it will short the current across a large power MOSFET, protecting my converter. The protection circuitry comes from Cameron Kiddoo's senior project [11].

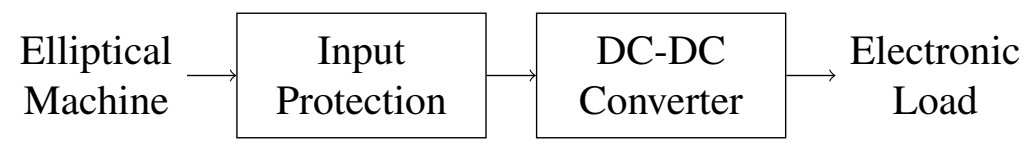

Figure 7.6: Elliptical-converter operation test setup

To test the elliptical machine output with the converter and an electronic load, I use the concept of "Minimum Strides Per Minute" to envision the elliptical machine's limits. For a fixed resistance on the elliptical machine and fixed electronic load, minimum strides per minute is defined as the slowest one can pedal on the elliptical and still produce a stable $36 \mathrm{~V}$ on the electronic load. Figure 7.7 shows the Minimum SPM curves current loads of $0.5 \mathrm{~A}$ and $1 \mathrm{~A}$.

These tests use the converter in burst mode, knowing that the converter faces lighter loads in the real world, and burst mode is ideal for lighter loads. Testers found it difficult to produce full curves for current loads over $1 \mathrm{~A}$. At lower resistances, it becomes difficult to pedal fast enough, and at higher resistances, it becomes difficult to pedal at all. This information suggests how difficult it is to generate more than $36 \mathrm{~W}$ on the elliptical machine with the EHFEM circuit connected in parallel with the already present load resistors. 
Minimum Strides per Minute vs. Resistance

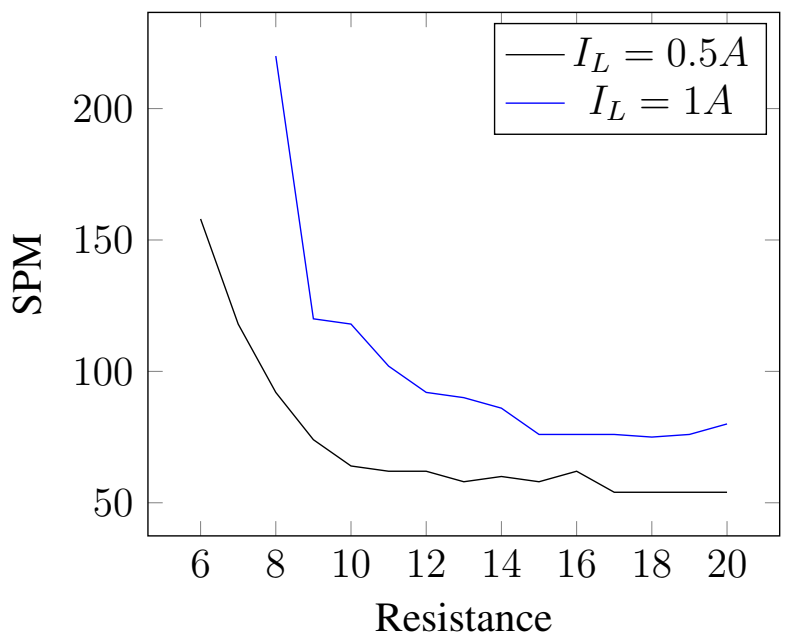

Figure 7.7: Minimum SPM necessary to meet a constant current load

\subsection{Converter to Inverter Integration Tests}

These tests ensure the compatibility between the DC-DC converter and the microinverter. Figure 7.8 shows a block diagram of the test setup.

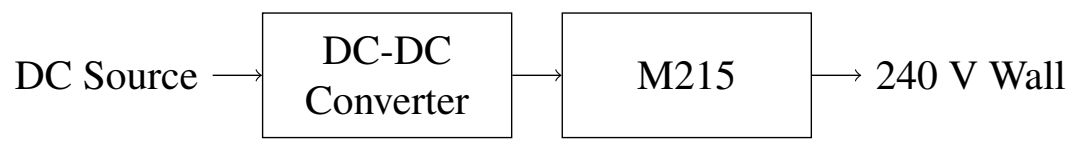

Figure 7.8: Converter to Inverter Integration Test Setup

James Ralston's senior project details the connection between the DC-DC converter, the microinverter, and the grid [17].

Initial testing shows the M215 microinverter delivering power to the grid after about 90 seconds. In a test with a $35 \mathrm{~V}$ DC source voltage and a current limit of $9.1 \mathrm{~A}$, the M215 initially delivers around $7 \mathrm{~W}$ to the grid. Over a period of two minutes, the M215 delivers increasingly more power to the grid. This trend continues until around the $25 \mathrm{~W}$ mark (the power meter fluctuates make a more accurate figure difficult to find), at which point the DC-DC converter output voltage drops.

This is the Maximum Power Point Tracking (MPPT) mechanism mentioned in the 
M215 advertising. The M215, expecting the IV curve of a solar panel, demands as much current as it can by dropping its input resistance.

The M215's MPPT algorithm presents a serious roadblock to full integration in a larger EHFEM system. The DC-DC converter does shore up the lower end of the elliptical machine output voltages and allow it to be used by the microinverter, but it lacks the current output capability demanded by the M215.

One proposed solution to this problem increases the output capacitance of the DC-DC converter. Conceivably, this stabilizes the input current seen by the M215 and convinces the MPPT to remain at the current input current. In practice, it failed to fix the issue and, at high DC source voltage, it destroyed the first three MOSFETs of the DC-DC converter.

At every cycle, the high current demand on the DC-DC converter causes a massive surge in the inductor current. By demanding too much input current, the M215 drops the output voltage of the DC-DC converter. Because the M215 cannot function with less than $22 \mathrm{~V}$ input, this shuts down the M215, which reduces the demand on the DC-DC converter and allows its output to rise to $36 \mathrm{~V}$. This creates a destructive cycle:

1. The M215 demands too much current from the DC-DC converter.

2. The DC-DC converter output voltage drops from $36 \mathrm{~V}$, below $22 \mathrm{~V}$.

3. The M215 shuts down from the low input voltage.

4. The DC-DC converter turns back on from lack of a load, rising back to $36 \mathrm{~V}$.

5. The M215 turns back on and demands too much current from the DC-DC converter.

To show this, this project inserts a $1 \mathrm{~m} \Omega$ resistor between the output of the DC-DC converter and the input of the M215 to monitor the current. A Tektronics oscilloscope on the resistor produces a waveform seen in Figure 7.9. The waveform suggests huge surge currents, up to $2 \mathrm{kA}$, at periodic intervals of about $75 \mathrm{~ms}$. Most likely, this comes from 
the output capacitors discharging quickly across the small input resistance presented by the M215.

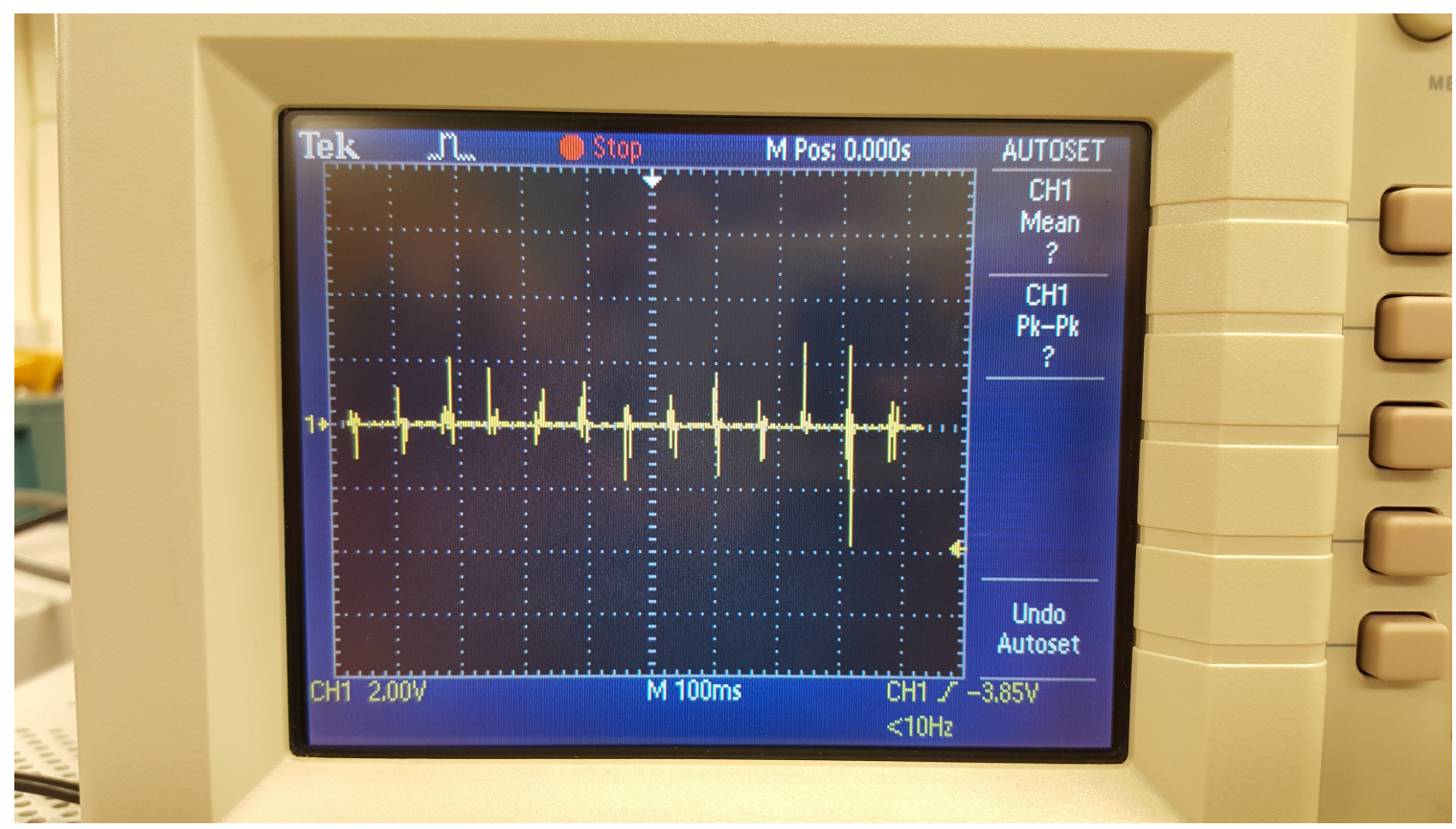

Figure 7.9: Current from DC-DC converter to microinverter. This is the voltage waveform across a $1 m \Omega$ resistor.

Reexamination of the test setup that produced Figure 7.9 shows that the oscilloscope probe grounded the input of the M215, which causes a Ground Fault Indication (GFI) on the microinverter.

The Envoy Communications Gateway lets a user clear fault conditions on the M215 using a web interface. After clearing the GFI on the M215:

1. When connected in the configuration shown in Figure 7.8 along with oscilloscope probes consistently raises the GFI. Simply connecting the ground connector of the oscilloscope probe to the DC negative terminal of the M215 causes a GFI.

2. Using a DC power source as input to the M215 lets the user clear the GFI, and when done so delivers power as intended.

Because this test measures the voltage difference across the sense resistor, clipping the oscilloscope probe grounds together but letting them float reliably gets the voltage 
difference without tripping a GFI. This effectively becomes a differential voltage probe, and it produces a useful waveform, shown in Figure 7.10.

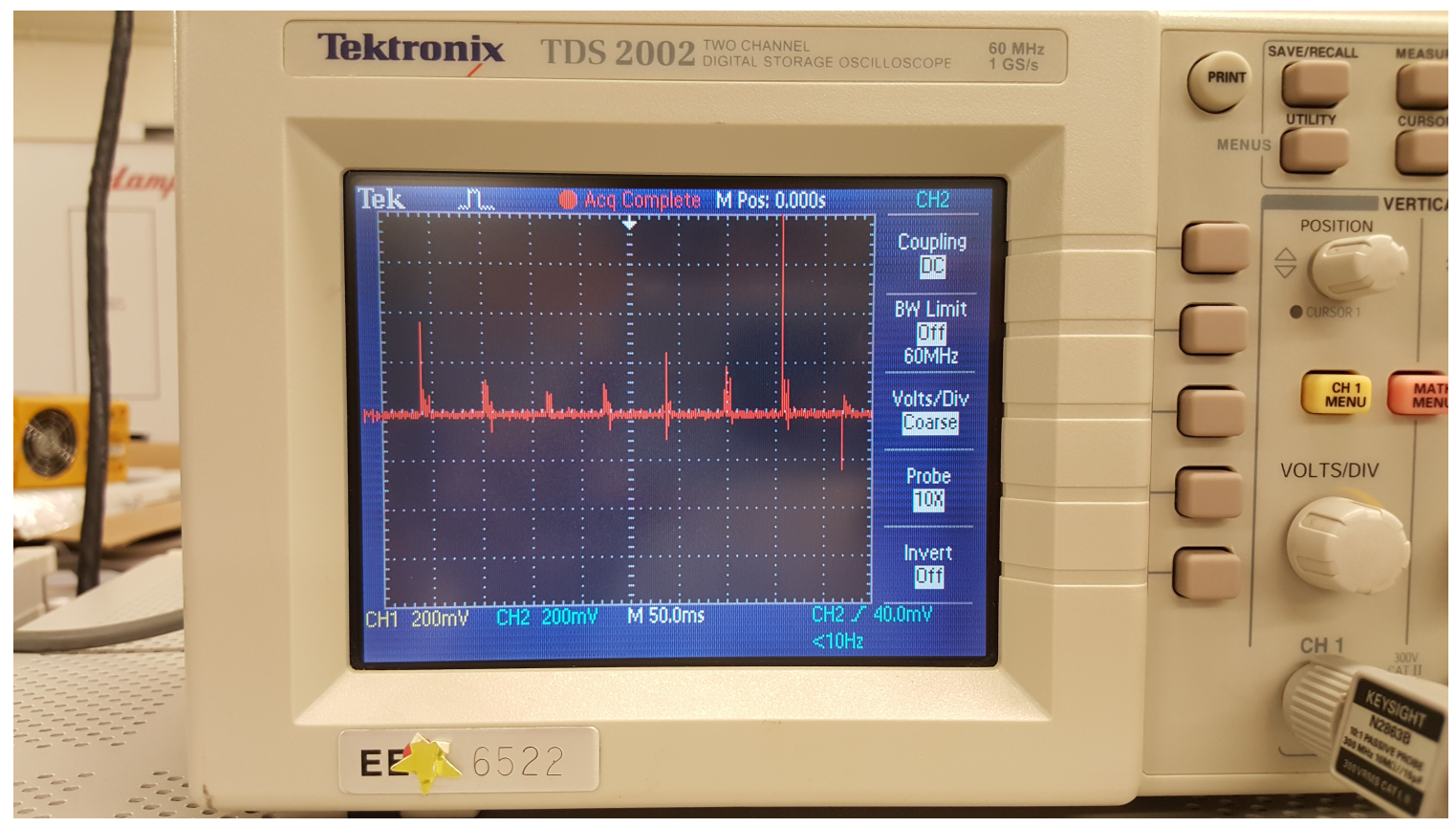

Figure 7.10: Converter-inverter current using a makeshift differential probe. $V_{i n}=35 \mathrm{~V}$ with 3 A current limit.

The waveform in Figure 7.10 agrees with the sound the converter makes when the inverter delivers power. It sounds like a clicking with a frequency that changes with the load current and input voltage. The inverter can sink a large amount of current for a short amount of time, causing the short spikes on the oscilloscope trace.

Creating a makeshift differential probe provided insight on the converter-inverter interaction, but the results of this integration test suggest that the M215 does not naturally fit into the EHFEM system.

This concludes the converter testing prematurely. The next chapter discusses solutions to this problem and others encountered in this project. 


\section{Chapter 8: Conclusion}

This report examines the feasibility of an EHFEM system using the M215 microinverter, a newly designed four-switch buck-boost converter, and the Precor elliptical machine. It details the process of converter design from simulation to fabrication, and dives into rigorous power MOSFET examination, acknowledging the high stress environment they encounter.

The four-switch buck-boost appropriately handles the wide voltage generated by the elliptical machine, as demonstrated by the converter-elliptical tests shown in Section 7.2. It consistently reached efficiencies above $90 \%$ across all tested loads, with an average of $91 \%$.

Selection of the FDMS86255 power MOSFET dramatically reduced the size of the PCB, which translates to savings in fabrication costs. This component decision came with the decision to use wide swaths of board copper as heat sinks, which also eliminated the need for large dedicated heat sinks and further lowered project costs. The total individual cost of the DC-DC converter came out to $\$ 92.39$. The M215 conservatively costs $\$ 150$, making the total material cost $\$ 242.39$, leaving $\$ 117.61$ for installation costs. Additionally, these space saving techniques let the DC-DC converter fit within the confines of the elliptical machine's shell.

The pedaling resistance of the elliptical machine clearly depends on the resistance seen at the terminals of the load resistors, but the DC-DC converter did not maintain constant resistance (as shown in Figure 7.4). To preserve the safety of the elliptical machine, input protection circuitry should maintain the $10 \Omega$ resistance that the elliptical machine expects. Figure 8.1 shows a possible scheme to accomplish this. MOSFETS M1 and M2 would add parallel resistance to lower the effective resistance of the circuit in the case that $R_{d c d c}$ ex-

ceeds $10 \Omega$. M4 adds series resistance in the case that $R_{d c d c}$ falls below $10 \Omega$. M2 hysteretically guides the transitions between these states. The control signals for the MOSFETs 
come from logical circuits using the voltage on the sense resistor, and force the circuits effective resistance to approach $10 \Omega$.

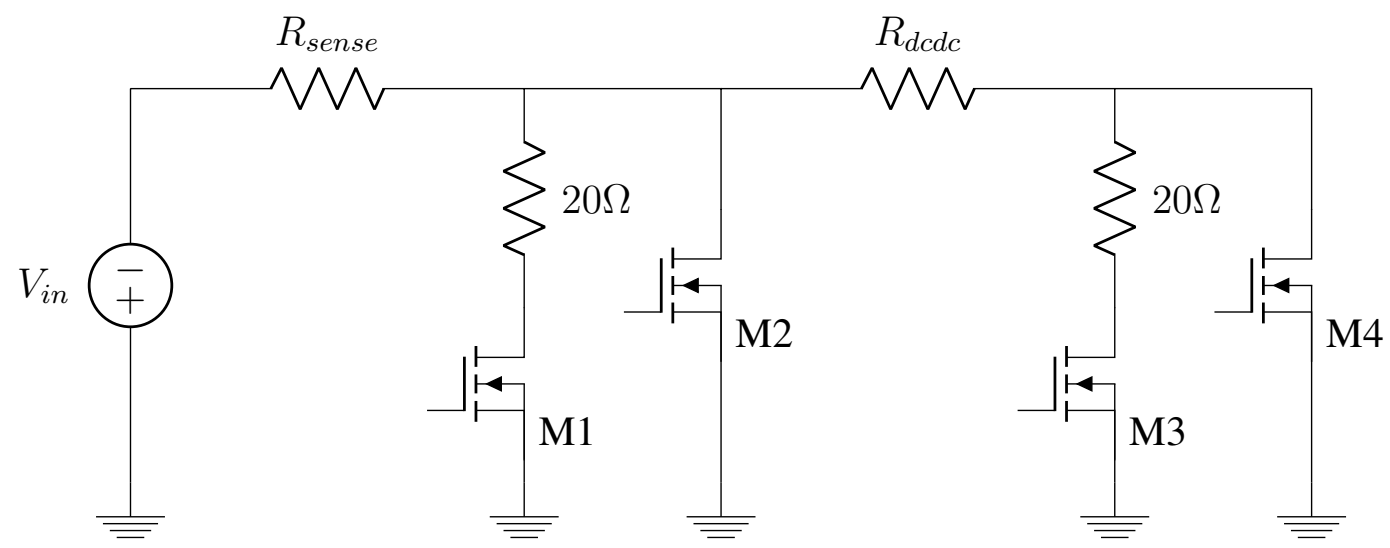

Figure 8.1: Proposed input protection circuit

As shown in Section 7.3, the MPPT functionality of the M215 microinverter runs counter to EHFEM interests. Because it expects the IV curve of a solar panel, the M215 draws the converter output too low and inhibits its own functionality. The EHFEM system probably benefits from a simpler inverter without such an algorithm. 


\section{BIBLIOGRAPHY}

[1] Linear, "Lt8705," Online, 2016, http://cds.linear.com/docs/en/datasheet/8705ff.pdf.

[2] IPCC, Summary for Policymakers. Cambridge, United Kingdom and New York, NY, USA: Cambridge University Press, 2013, book section SPM, p. 130. [Online]. Available: www.climatechange2013.org

[3] T. Dean, The Human-Powered Home: Choosing Muscles Over Motors. New Society Publishers, 112008.

[4] ReRev, "A renewable energy revolution," Online, 2011, http://www.rerev.com.

[5] Rhymebus, "Fitness green power station," Online, 2014, http://www.rhymebus.com. tw/files_web/R-Rider.

[6] Gyre9, “The green revolution,” Online, 2014, http://www.gyre9.com/portfolio-item/ the-green-revolution/.

[7] M. Kou, "Energy harvesting from elliptical machines: Dc-dc converter design using sepic topology," Master's thesis, Cal Poly San Luis Obispo, 2012, http: //digitalcommons.calpoly.edu/theses/753/.

[8] G. Hollister, "Elliptical machine dc-dc converter for the energy harvesting from exercise machines project," 2011, http://digitalcommons.calpoly.edu/eesp/70/.

[9] R. Rickard and L. Stowe, "Exercise bicycle dc-dc converter for the energy harvesting from exercise machines project," 2011, http://digitalcommons.calpoly.edu/eesp/97/.

[10] B. D. Yoo and S. T. K. M. Chu, "Buck-boost dc-de converter with input protection system for the energy harvesting from exercise machines project," 2014, http://digitalcommons.calpoly.edu/eesp/258/. 
[11] E. Funsten and C. Kiddoo, "Protection system for the energy harvesting from exercise machines (ehfem) project," 2014, http://digitalcommons.calpoly.edu/eesp/259/.

[12] R. Turner and Z. Weiler, "Dc-dc converter input protection system for the energy harvesting from exercise machines (ehfem) project," 2013, http://digitalcommons. calpoly.edu/eesp/214/.

[13] A. Chernetz, "Exercise power grid display and web interface," 2009, http:// digitalcommons.calpoly.edu/cpesp/2/.

[14] B. Asche, "Near real-time exercise machine power statistics reporting," Master's thesis, Cal Poly San Luis Obispo, 2010, http://digitalcommons.calpoly.edu/theses/241/.

[15] A. Hilario, "Energy harvesting from elliptical machines using four switch buck boost technology," Master's thesis, Cal Poly San Luis Obispo, 2011, http://digitalcommons. calpoly.edu/theses/511/.

[16] D. Braun, "Braun's senior projects," Online, August 2014, https://courseware.ee. calpoly.edu/ dbraun/srproj.htm.

[17] J. Ralston, "Micro-inverter improvement for the energy harvesting from exercise machine project," 2016, http://digitalcommons.calpoly.edu/eesp/354/.

[18] Enphase, "M215," Online, 2016, http://www.enphase.com/sites/default/files/M215 DS_EN_60Hz.pdf.

[19] "Resistor value and ratio calculator," Online, December 2015, http://jansson.us/ resistors.html.

[20] L. Technology, "Linear technology - design simulation and device models," Online, 2016, http://www.linear.com/designtools/software/\#LTspice.

[21] Linear, "Lt8705 telecom voltage stabilizer," Online, 2016, http://www.linear.com/ solutions/4501. 
[22] B. Burk, R. Bhula, and N. McKay, "Energy harvesting from exercise machines: Lt8705 dc-dc conversion for elliptical trainers," 2014, http://digitalcommons.calpoly. edu/eesp/279/.

[23] ONSemi, "Fdms86255 datasheet," Online, March 2015, http://www.mouser.com/ds/ 2/149/FDMS86255-533280.pdf.

[24] A. Young, "Automated data acquisistion in electronic circuit laboratories," Master's thesis, Cal Poly San Luis Obispo, 2003. [Online]. Available: courseware.ee.calpoly. edu/ dbraun/ayoung/contents.html

[25] ExpressPCB, "Pcb layout software," Online, 2017, https://www.expresspcb.com/ expresspcb/.

[26] KiCad, "Kicad eda," Online, 2017, http://kicad-pcb.org/.

[27] Precor, "Ellipticals_-home exercise equipment," Online, 2016, http://www.precor. com/en-us/home/products/ellipticals.

[28] EIA, "Electricity in the united states," Online, 2016, http://www.eia.gov/ energyexplained/index.cfm?page=electricity_in_the_united_states.

[29] J. Kaiman, "Rare earth mining in china: the bleak social and environmental costs," The Guardian, 2014, http://www.theguardian.com/sustainable-business/ rare-earth-mining-china-social-environmental-costs. 


\section{Appendix A: Senior Project Analysis}

Project Title Energy Harvesting From Exercise Machines - Buck-Boost Converter

Student's Name

Andrew Forster

Advisor's Name

David Braun

\section{A.1 Summary of Functional Requirements}

This project involves the design of a DC-DC converter that steps up or steps down a 10 to $60 \mathrm{~V}$ Input from the exercise machine into a $36 \mathrm{~V}$ output that the M215 Microinverter can efficiently use. Cal Poly has the microinverter and elliptical machine, but to fulfill Cal Poly need to save money and energy, the EHFEM project requires a DC-DC converter that can handle the wide range of input voltages and provide a consistent output.

Chapter 2 further discusses functional requirements.

\section{A.2 Primary Constraints}

To optimize the energy harvested, the converter requires a power efficiency of at least $80 \%$ over a wide input voltage range. The elliptical machine outputs up to $245 \mathrm{~W}$ and a DC-DC converter needs to maintain its efficiency for all voltage levels.

The converter replaces two $20 \Omega$ resistors in parallel, designed in the elliptical machine to dissipate excess power. Because the modifications to the machine maintain the user experience associated with the device, the converter needs a consistent input impedance of $10 \Omega$.

The maximum current delivered to the load should be $7 \mathrm{~A}$. The inductor's saturation current should be less than 15 A. The MOSFETs should be capable of dissipating the power generated from switching.

Physically, the converter and microinverter together fit into the shell of the elliptical 
machine, to not get in the way of anyone that wants to use the machine. A converter box next to each machine in a set would crowd the gym and limit the maximum number of machines.

Chapter 2 further discusses project constraints.

\section{A.3 Economic}

The project involves a set of economic benefits for consumers and for the utility companies. By eliminating the heat generated in large resistors, the consumer saves money on HVAC costs. The energy harvested also cuts down on electricity costs and saves the utility company money by preventing power dissipation in the transmission lines. With proper advertising, the EHFEM project also fits easily into the "green" marketing approach, which has the potential to boost gym membership and encourage the use of the machines.

Where used, EHFEM machines have the potential to drive gym prices up. The alterations and additional materials make each machine more expensive, and the gym owner builds a brand by incorporating eco-friendly machines.

Installation of a grid-connection system requires investment, but the gym recuperates that cost in electric power savings over time. With a ten year lifespan, a 3\% rate of inflation in energy prices, a lifetime degradation factor of a half a percent, 12 hours of daily usage, and an average of $100 \mathrm{~W}$ generation, the project grants a leeway of $\$ 360$ dollars for the added cost to the machine.

The EHFEM modification may outlive the elliptical machine. In that case, a technician can move the extra hardware to another elliptical. These extra installation costs can pay themselves off and the new elliptical might actually reduce in net cost over time.

Section 2.4 further details project costs and the bill of materials. 


\section{A.4 If manufactured on a commercial basis}

Ideally, each elliptical machine comes with this functionality built in, taking advantage of the scalability of industrial processes and eliminating the installation cost attached to retrofitting an already manufactured product.

To prevent the modification from pushing the elliptical machine into a higher price point, the addition should cost less than $\$ 360$ if it pays itself off within ten years.

The EHFEM system adds around $\$ 250$ to the price of the machine if the manufacturer installs it, which eliminates installation costs. The DC-DC converter costs $\$ 92.39$ and the M215 microinverter costs around \$150. Cables add a small fudge factor for the total price.

Precor's cheapest elliptical machine, the EFX 221 Energy Series, costs \$2,199 [27]. The EHFEM system raises the price by 11-12\%.

\section{A.5 Environmental}

Grid power is highly carbon based. As of $2015,66 \%$ of electricity in the US comes from coal or natural gas [28]. EHFEM reduces fossil fuel consumption by reducing grid usage. Additionally, EHFEM keeps the gym cool and avoids air conditioning energy costs. EHFEM principally seeks to reduce carbon dioxide footprint by reducing grid footprint. Possibly more valuable, EHFEM encourages the common gym goer to mind their environmental impact regularly.

Electronics manufacturing significantly harms the environment, however. Rare earth metal mining spoils drinking water and improper disposal of electronics pollutes whole communities, especially in China [29].

EHFEM adheres to the RoHS standard, which mandates lead-free solder. Lead ranks high among the toxic materials that poison communities dedicated to recycling electronics. EHFEM responsibly avoids introducing toxic materials into the environment. 


\section{A.6 Manufacturability}

The electronics for the EHFEM project require only generic PCB fabrication. This involves standard precautions against electrostatic discharge, board warping from the solder solidification process, and thermal imbalance by component placement.

Component sourcing concerns manufacturing as well. The average inductor current must reach 7.5 A without saturating, and minimize series resistance. For safe oversizing, and accounting for current ripple, this means a saturation current of at least $20 \mathrm{~A}$. The input capacitors and MOSFETs must withstand nominal input voltages of up to $50 \mathrm{~V}$, which means voltage ratings of at least $100 \mathrm{~V}$, to account for ripple and possible overshoot.

The elliptical machine can include the converter module, or a machine or a technical expert can retrofit an existing machine.

\section{A.7 Sustainability}

The project promotes sustainability by shifting focus from centralized, non-renewable energy sources to lower impact, distributed energy generation. It increases energy supply and reduces energy demand by reducing HVAC costs.

The design would benefit from providing a visual indicator of energy harvested or

power generated. The result motivates the user to use the machine, which results in more gym goers and more energy savings.

\section{A.8 Ethical}

EHFEM plays on the psychological egoism that accompanies the thought of generating energy. Producing energy through hard work, aiding in energy independence, and reducing environmental impact attracts a culture that makes huge efforts to value it. People feel good for doing good, especially when it benefits them.

From a utilitarian perspective, the machine encourages the user to work out, because it 
benefits them and the environment, doing the most good for the most people. It encourages the gym owner to employ an energy harvesting machine as a long term investment.

The IEEE code of ethics mandates avoiding the injury of others by false or malicious action. EHFEM adheres to this principle by adhering to NEC standards and keeping all additional components within the shell of the elliptical machine.

\section{A.9 Health and Safety}

Any alterations to an exercise machine must comply with industry standards concerning electrical insulation, protection circuitry, and properly rated components. As long as the circuit functions properly, the elliptical machine works as intended, and the health benefits of a cardiovascular workout apply.

\section{A.10 Social and Political}

Modern America suffers from a lack of environmental awareness and a lack of incentive to address the associated problems. Wind turbines and solar farms receive well enough support, but the NIMBY attitude stems from a lack of immediate feedback. The EHFEM project is a microcosm of this attitude. EHFEM reduces the choice to choosing a gridconnected elliptical machine over a grid-naïve machine. Projects like these represent slight cultural shifts that evolve into the political decisions of the future.

Unfortunately, electronics motivate politics across the globe. Both in production and disposal, electronics can harm the environment. Tantalum capacitors require coltan, which started a rebellion in Congo in the 90s. Rare earth metal mining techniques spoil local drinking water in China [29].

This project slightly favors larger gym owners over smaller gym owners. While EHFEM minimizes the price added to the elliptical machine, it inevitably makes the product more expensive in the short term. A larger gym can more likely afford the up front cost of the grid-tied elliptical machines and save money in the long term. The larger also benefits from 
the green marketing angle in the meantime.

This project favors gyms in general over the individual consumer. The cash-strapped personal elliptical trainer market avoids extra costs, and the average consumer doesn't have $240 \mathrm{~V}$ plug in their home.

\section{A.11 Development}

Early on, this project taught me the value of deliberate and methodical development. The converter simulations took upwards of two hours each, invalidating the previous approach of rapid simulation without thought. Each new simulation has a goal or a question to answer.

Over the course of this project, I have learned much about PCB design and fabrication, external to the Cal Poly curriculum.

Surface mount soldering and PCB layout are invaluable skills. The power electronics discipline emphasizes the mindset of separating power ground and signal ground and designing tight, self-contained power loops, all in the name of signal integrity.

Also, hardware can be reconfigured. For example, the LT8705 has a MODE pin that changes the converter behavior if driven to ground, above $2.5 \mathrm{~V}$, or left floating. Instead of hard wiring this design decision, externalize the pin with a header so the decision comes after fabrication. Other tricks work around the relative permanency of fabrication. Include multiple footprints in parallel even though they might go unused in the final design. Use $0 \Omega$ resistors to alter the circuit topology after the fact. Breakout critical nodes for troubleshooting. In general, delay design commitments unless absolutely necessary. 